NOTICE: this is the author's version of a work that was accepted for publication in Food Chemistry. Changes resulting from the publishing process, such as peer review, editing, corrections, structural formatting, and other quality control mechanisms may not be reflected in this document. Changes may have been made to this work since it was submitted for publication. A definitive version was subsequently published in Food Chemistry, Volume 135, Issue 2, November 2012, Pages 787-798, http://dx.doi.org/10.1016/j.foodchem.2012.05.036 


\section{Exposure of grapes to smoke of vegetation with varying lignin composition and accretion of lignin derived putative smoke taint compounds in wine}

David Kelly ${ }^{\mathrm{a}}$, Ayalsew Zerihun ${ }^{\mathrm{a}, *}$, Davinder P Singh ${ }^{\mathrm{b}}$, Christiane Vitzthum von Eckstaedt $^{\mathrm{c}}$, Mark Gibberd ${ }^{\mathrm{a}}$, Kliti Grice ${ }^{\mathrm{c}}$ and Mark Downey ${ }^{\mathrm{b}}$

${ }^{a}$ Department of Environment and Agriculture, Curtin University, Margaret River Education Campus, Margaret River, WA, 6285, Australia

${ }^{\mathrm{b}}$ Department of Primary Industries Victoria, Mildura, Victoria, 3502, Australia

${ }^{c}$ WA-Organic and Isotope Geochemistry Centre, The Institute for Geoscience Research, Department of Chemistry, Curtin University, Perth, WA 6845, Australia

Running title: lignin composition of pyrolysed fuel and smoke taint in wine

*Corresponding author: Tel: +618 9780 5826; Fax: +618 97579395

E-mail: A.Zerihun@curtin.edu.au (A. Zerihun) 


\begin{abstract}
Smoke taint in wines from bushfire smoke exposure has become a concern for wine producers. Smoke taint compounds are primarily derived from pyrolysis of the lignin component of fuels. This work examined the influence of the lignin composition of pyrolysed vegetation on the types of putative smoke taint compounds that accrue in wines. At véraison, Merlot vines were exposed to smoke generated from five vegetation types with differing lignin composition. Smoke was generated under pyrolysis conditions that simulated bushfire temperature profiles. Lignin and smoke composition of each fuel type along with putative smoke taint compounds in wines were determined. The results showed that, regardless of fuel type, the commonly reported guaiacyl lignin derived smoke taint compounds, guaiacol and 4methylguaiacol, represented about $20 \%$ of the total phenols in wines. Quantitatively, syringyl lignin derived compounds dominated the total phenol pools in both free and bound forms. The contributions of $p$-hydroxyphenyls were generally similar to the guaiacyl sources. A further unexpected outcome of the study was that pine smoke affected wines had significantly elevated levels of syringols compared to the controls although pine fuel and its smoke emission lacked syringyl products.
\end{abstract}

\title{
Highlights
}

Links between vegetation lignin composition and smoke taint in wine were explored. Wines contained phenols other than guaiacols- the common smoke taint measures. These other significant phenols are phenol, $o^{-}, m$ - and $p$-cresol and syringol. Pine fuel smoke with no syringyls caused significantly elevated syringol in wines.

\section{Keywords}


Acid Hydrolysis, Glycosides, Lignin composition, Py GC-MS, Smoke exposure, Smoke taint, TD GC-MS, Vitis Vinifera L. cv. Merlot, Volatile phenols, Wine.

\section{Introduction}

Much of the global wine grape crop is produced in Mediterranean-type environments (Jones et al., 2005) where fire is a frequent occurrence (Keeley et al., 2011). While fire and the resultant smoke play an influential role in shaping natural ecosystems in these environments (Keeley et al., 2011), smoke from such fires can also potentially taint grapes and consequently wines if smoke drifts through vineyards in the landscape while vines are bearing fruit (Whiting \& Kristic, 2007). Several recent investigations of smoke exposure from either experimental fires using model vegetation fuels (Kennison et al., 2008; Sheppard, Dehsi, \& Eggers, 2009) or wild/prescribed fires (Hayasaka et al., 2010a; Singh et al., 2011, in Press) have established that grapes exposed to smoke from pyrolysis of vegetation fuels produce wines with elevated levels of substituted phenols that impart undesirable organoleptic properties.

Smoke-borne compounds that are considered responsible for smoke taint in grapes or wines are thought to originate primarily from pyrolysis of the lignin component of vegetation fuels (Hayasaka et al., 2010a; Singh et al., in Press) analogously to that which occurs in smoke used for curing/flavouring of food (Gilbert \& Knowles, 1975; Tóth \& Potthast, 1984; Wittkowski et al., 1992). Lignin is derived mainly from polymerisation of three monolignol precursors: p-coumaryl alcohol, coniferyl alcohol and sinapyl alcohol (Pettersen, 1984; Fahmi et al., 2007; Weng \& Chapple, 2010), which respectively constitute the $p$ hydroxyphenyl, guaiacyl and syringyl units of lignin. When pyrolysed, these lignin units release respectively phenol, guaiacol and syringol along with their substituted forms such as methyl, ethyl, propyl, vinyl, allyl, propenyl (Gilbert \& Knowles, 1975). The lignin makeup 
broadly varies with vegetation type. Lignin of grasses contains all three precursors (Ralph \& Hatfield, 1991; Fahmi et al., 2007; Buranov \& Mazza, 2008); in lignin of angiosperm hardwoods, syringyl units dominate while most of the balance is from guaiacyl units with a minor contribution of $p$-hydroxyphenyl units (Pettersen, 1984; Rencoret et al., 2011); whereas lignin of gymnosperms, such as pines, predominantly contains guaiacyl units with some $p$-hydroxyphenyls but lacks syringyl units (Lebo, Gargulak, \& McNally, 2001; Pettersen, 1984; Weng \& Chapple, 2010).

Several variables can affect the composition of lignin pyrolysis products in smoke and subsequently the types of lignin-derived putative smoke taint compounds that accrue in wines made from smoke exposed grapes. These include firstly, the monolignol composition of pyrolysed vegetation. Even for a given vegetation, its lignin makeup may vary as a function of its age (Rencoret et al., 2011), the proportion of various plant components (Yokoi et al., 1999), and state of decay of the fuel which can alter the monolignol composition due to preferential demethoxylation of the dimethoxy- or methoxy-substituted phenylpropanoid units, i.e., degradation of syringyl and/or guaiacyl units, by rot-fungi (Vane et al., 2005; Faix et al., 1991; Schmidt, 2006; Higuchi, 1990 and references therein). Secondly, pyrolysis conditions, particularly temperature and oxygen availability (Simon et al., 2005; Guillén \& Ibargoitia, 1996; Tóth \& Potthast, 1984) can affect lignin pyrolysis products. While lignin may start to pyrolyse at temperatures as low as $280-290^{\circ} \mathrm{C}$ (Browne, 1958; Butt, 2006), the composition of lignin pyrolysis products varies as temperature increases, with yields of the organoleptically important phenolic compounds in smoke reportedly peaking in the region of $559^{\circ} \mathrm{C}$ (Guillén \& Ibargoitia,1996) and $650^{\circ} \mathrm{C}$ (Tóth \& Potthast, 1984). The above variables underscore the need to define vegetation type, fuel and pyrolysis conditions and smoke composition in order to compare results across studies as well as to explore the links between these factors and the types of putative taint compounds that accrue in grapes and wines. 
However, such definitions are rather rare in most of the smoke taint studies in grapes and wines to date.

The earlier work on smoke taint in grapes and wines focussed on two guaiacyl lignin derived phenols: guaiacol and 4-methyl guaiacol (Kennison et al., 2007, 2008; Sheppard et al., 2009). However, it has been pointed out that smoke affected wines have sensory properties additional to those expected from these two phenols. This suggests other phenols in smoke are contributing to the extra undesirable sensory effects. Recently, Hayasaka et al. (2010a) and Singh et al. (in Press) have shown that there are indeed several lignin pyrolysis products in bushfire smoke affected wines at elevated levels. Although these findings broaden our understanding of the range of putative taint compounds that can accrue in wine as a result of smoke exposure, these do not allow for exploring the link, if any, between vegetation type of the smoke source and the types of taint compounds that accrue in grapes or wines.

In the work reported here, a controlled and replicated smoke generation experiment was carried out using vegetation fuel sources that differed in their lignin makeup. The aim was to expose fruit-bearing mature Merlot vines to the resultant smoke and to examine the accretion of putative smoke taint compounds in wines in relation to the lignin makeup of the fuels as well as the smoke emissions. For this purpose, five distinct and major vegetation types with varying lignin composition were used. Each fuel type was (1) reconstituted in proportion to biomass components that burn in a decadal fire event and (2) pyrolysed under conditions that reproduce wildfire temperature profiles (Gould et al., 2007). Recent work has shown that, at least in young wines, the putative smoke taint compounds are predominantly sequestered as glycoconjugates and only a small proportion is present as volatile phenols (Hayasaka et al., 2010a; Singh et al., 2011, Singh et al., in Press; Kennison et al., 2008; Wilkinson et al., 2011). Thus, in this study both volatile and glycoside-bound phenols were considered. 


\section{Materials and Methods}

\subsection{Fuel types and fuel compilation}

The experiment was carried out in the Margaret River wine region $\left(33^{\circ} 57^{\prime} \mathrm{S}, 115^{\circ} 01^{\prime} \mathrm{E}\right)$, in the south west of Western Australia. In this viticultural region, vineyards typically adjoin forested and/or grassed landscapes. The vegetation of these landscapes contains mainly hardwood species such as jarrah (Eucalyptus marginata Donn ex Sm.), karri (E. diversicolor F. Muell.) and marri (Corymbia calophylla Lindl.); plantations of the softwood species radiata pine (Pinus radiata D. Don.); and pasture grasses such as wild oats (Avena fatua L.). Thus, for this study, five biomass fuels representing each of these main vegetation types were used as fuel sources. The fuels were stored in thin layers for several weeks to equilibrate their moisture contents. After drying, each of the tree fuels for smoke generation was compiled from foliage, duff, twigs $(\varnothing<6 \mathrm{~mm})$ and round wood $(\varnothing \geq 6 \mathrm{~mm})$ in proportion to the respective components that occur in a 10 year old fuel accumulation (Burrows, 1994; O’Connell \& Menage, 1982) (supplementary Table S1). For wild oats, all of its above ground biomass was considered a single component (100\% fuel source) since all of it combusts during a fire event.

\subsection{Grapevine smoke exposure experiment}

The smoke exposure experiment was set up as a completely randomised block design in a commercial vineyard containing 10 year old Vitis vinifera L. cv. Merlot vines. To minimise variability in experimental units within a block, each block was carefully selected for vines of uniform canopy size and crop load. The treatments, for smoke generation and exposure, consisted of the five vegetation fuel types described above plus a control (i.e., vines not exposed to smoke). Within each block, the treatments plus the control were randomly 
allocated to experimental units. Each experimental unit consisted of a panel of five vines. Experimental units were separated by at least two panels of vines to avoid smoke cross contamination. Each block containing the full treatment structure was replicated five times, thus there were a total of 30 experimental units.

Smoke exposure of the experimental vines was carried out, $14 \mathrm{~d}$ post-veraison, in a purpose built tent as described by Kennison et al. (2008). For smoke generation, $1 \mathrm{~kg}$ of fuel sample was combusted inside a custom built pyrolysis chamber that allowed a controlled replication of the wild fire temperature versus time profiles reported in Gould et al. (2007). The resulting smoke was delivered, via a flexible steel tube, to a $63 \mathrm{~m}^{3}$ tent enclosing each replicate vine panel. Each smoke exposure event lasted 30 minutes. The smoke density defined as an obscuration by particulate matter larger than $2.5 \mu \mathrm{m}\left(\mathrm{PM}_{2.5}\right)$ - was recorded for the entire duration of each smoke exposure event using a Laser Focus VLF-250 nephelometer (Xtralis, Mawson Lakes, South Australia). In each case, obscuration exceeded the instrument's maximum reading of $32 \%$. Control vines were similarly enclosed in an identical tent for the same duration to minimise differences in environmental conditions between smoke treated and control vines.

\subsection{Harvest and vine size assessments}

The fruits from each replicate panel were harvested separately at commercial maturity, total soluble solids of $\sim 23{ }^{\circ}$ Brix, six weeks after smoking treatments. The mass of fruit from each replicate, as well as the number of bunches and the mass of 200 randomly selected berries were determined. Leaf area per panel was estimated from the product of average leaf area per cane and the total number of canes per panel. Details on harvest and leaf area are given in supplementary Table S2. 


\subsection{Wine making}

The fruit from each replicate was kept separate and wines made individually for each of the 30 samples. Each lot was crushed and de-stemmed with the addition of $100 \mathrm{mg} / \mathrm{L}$ potassium metabisulphite. The total acids were adjusted to $7.0 \mathrm{~g} / \mathrm{L}$ with the addition of tartaric acid. The must was inoculated with 300 mg/L Saccharomyces cerevisiae EC1118 (Lallemand Inc., Montreal, Canada) and $100 \mathrm{mg} / \mathrm{L}$ diammonium phosphate added as a nitrogen supplement. Each replicate was fermented on skins in open neck $25 \mathrm{~L}$ glass demijohns and hand plunged regularly. The specific gravity and temperature were recorded every $12 \mathrm{~h}$. At $3^{\circ}$ Brix the must was pressed off the skins and fermentation continued to dryness $(<1 \mathrm{~g} / \mathrm{L}$ residual sugars $)$ in capped 15 L demijohns. Each replicate was racked from gross lees and inoculated with Oenococcus oeni (Viniflora CH 16, CHR Hansen, Denmark) at $10 \mathrm{mg} / \mathrm{L}$ to initiate malolactic conversion. The ferments were kept at $23{ }^{\circ} \mathrm{C}$ until malic acid levels stabilised $(<0.1 \mathrm{~g} / \mathrm{L}$ malic acid). Upon completion of malolactic fermentation, the wines received a further 60 $\mathrm{mg} / \mathrm{L}$ potassium metabisulphite and cold stabilised at $-4^{\circ} \mathrm{C}$ for $21 \mathrm{~d}$, filtered through a $0.2 \mu \mathrm{m}$ pore size cartridge (Sartorius Sartopure 2 Maxicap, Sartorius, Gottingen, Germany) and bottled under food grade nitrogen with stelvin closures.

\subsection{Smoke sampling during the vine smoke exposure experiment and prescribed burns}

Samples of smoke generated during the vineyard smoke exposure experiments and prescribed burning were collected using a Markes Unity 2 thermal desorption (TD) unit (Markes International Ltd, Llantrisant, UK) as described by Vitzthum von Eckstaedt et al. (2011). The TD sampling tubes were packed manually with approximately $280 \mathrm{mg}$ Tenax-TA adsorbent (60-80 mesh) with minimal compression. All tubes were thermally conditioned for 4 hours at $330^{\circ} \mathrm{C}$ prior to their first use and for $30 \mathrm{~min}$ at $310^{\circ} \mathrm{C}$ prior to every sampling event. In the vineyard trials, smoke was drawn through at a rate of $200 \mathrm{~mL} / \mathrm{min}$ with a miniport diaphragm 
pump (KNF Neuberger GmbH, Breisgau, Germany) for $30 \mathrm{~min}$. Full details of the prescribed burn sampling procedure are given in supplementary Fig. S1. The sample tubes were stored at $4^{\circ} \mathrm{C}$ until analysed.

\subsection{Chemical analyses}

\subsubsection{Lignocellulose analysis}

For each fuel type, $1 \mathrm{~kg}$ samples were reconstituted in proportion to the components listed in Table S1. Subsamples were then analysed for cellulose, hemicellulose and lignin at the Western Australian Chemistry Centre (Perth) according to the method of van Soest \& Wine (1967). Each analyte was determined in triplicate.

\subsubsection{Lignin composition of fuels via pyrolysis gas chromatography-mass spectrometry (Py} $G C-M S)$

For lignin composition analysis, subsamples of fuels reconstituted as described above were pulverized to $<0.5 \mu \mathrm{m}$ particle size. Approximately $0.1 \mathrm{mg}$ was then weighed into quartz tubes and flash pyrolysed for $20 \mathrm{sec}$ at $550^{\circ} \mathrm{C}$ using a CDS Analytical 5250 Automated Pyroprobe (Oxford, Pennsylvania, USA). The transfer line from the pyroprobe to the GC-MS system was operated at $300^{\circ} \mathrm{C}$ and the GC-MS analyses were performed on an HP6890A Gas Chromatograph (Hewlett Packard, Santa Clara, California, USA) interfaced to an HP5973A Mass Selective Detector. A $60 \mathrm{~m}$ x $0.25 \mathrm{~mm}$ x $0.25 \mu \mathrm{m}$ DB-5MS capillary column (Agilent J\&W, Santa Clara, USA) was used for the analyses with a helium carrier in constant flow mode at $1.2 \mathrm{~mL} / \mathrm{min}$ with a $40: 1$ inlet split. The $\mathrm{GC}$ oven was cooled to $-20^{\circ} \mathrm{C}$, held for $1 \mathrm{~min}$ and then heated at $8^{\circ} \mathrm{C} / \mathrm{min}$ to $40^{\circ} \mathrm{C}$. The oven temperature was then ramped to $320^{\circ} \mathrm{C}$ at $4^{\circ} \mathrm{C} / \mathrm{min}$ and held at $320^{\circ} \mathrm{C}$ for $25 \mathrm{~min}$. The mass selective detector was scanned between $\mathrm{m} / \mathrm{z}$ 20 and 620, at 2.48 scans per second with an electron energy of $70 \mathrm{eV}$. All the analyses were 
carried out in triplicate. The lignin derived compounds were identified by comparing their mass spectra with the NIST and/or Wiley spectral libraries or by comparison to reported spectra in the literature (Ralph \& Hatfield, 1991). Individual lignin pyrolysates were quantified by their relative percentage area of the total ion chromatograms of all the lignin pyrolysates.

\subsubsection{Smoke composition}

The smoke samples were analysed by thermal desorption gas chromatography mass spectrometry (TD GC-MS) on an HP6890A GC interfaced to an HP5973A Mass Selective Detector and Unity 2 single tube, two stage desorption unit as described in Bates et al. (2008) and Vitzthum von Eckstaedt et al. (2011). Briefly, the smoke sample containing tubes were thermally desorbed at $300^{\circ} \mathrm{C}$ for 5 min (first stage desorption); the desorbed samples were transferred in a helium gas stream $(>25 \mathrm{~mL} / \mathrm{min})$ to a cold trap $\left(10^{\circ} \mathrm{C}\right)$ to refocus the compounds. The refocusing cold trap was subsequently heated at $100^{\circ} \mathrm{C} / \mathrm{sec}$ to $300^{\circ} \mathrm{C}$ and held isothermally for $1 \mathrm{~min}$ (second stage desorption). The compounds desorbed from the refocusing trap were transferred, in a helium stream at $1 \mathrm{~mL} / \mathrm{min}$, to the GC column via a deactivated fused silica capillary transfer line that was maintained at $120^{\circ} \mathrm{C}$. Samples were analysed on a $60 \mathrm{~m}$ x $0.25 \mathrm{~mm} \times 0.25 \mu \mathrm{m}$ Agilent DB5-MS column with a helium carrier gas in constant flow mode at $1.1 \mathrm{~mL} / \mathrm{min}$. The GC was set at constant pressure and run in splitless mode. All sample splits were carried out at the desorption stage. The DB-5MS column was run with an initial temperature of $40^{\circ} \mathrm{C}$ ramped at $4^{\circ} \mathrm{C} / \mathrm{min}$ to $300^{\circ} \mathrm{C}$ and held isothermally for $10 \mathrm{~min}$.

\subsubsection{Free and glycoside-bound putative smoke taint compounds in wines}

Lignin-derived putative smoke taint (volatiles and glycoside-bound forms) compounds in wines were extracted and analysed using GC-MS as described by Singh et al. (2011; in 
Press). In the present study, the glycoside-bound lignin pyrolysis products in wines refer to values determined after strong acid hydrolysis as detailed in Singh et al. (in Press).

\subsection{Data analyses}

Data were analysed according to a completely randomised block design model (with one factor and five replicates). Reported treatment effects discussed herein, unless indicated otherwise, were significant at $\mathrm{p}<0.05$. Analyses were carried out using SPSS $20\left(\right.$ IBM $^{\circledR}$ SPSS $^{\circledR}$ Statistics) and GenStat $13^{\text {th }}$ Edition (VSN International Ltd., UK).

\section{Results}

\subsection{Lignocellulose composition of fuels}

The cellulose contents of all fuels varied over a relatively narrow range (24 to 29\%) except in oat for which cellulose made up about half of the fuel mass (Table 1). The hemicellulose contents of the tree fuels (hardwood or softwood) were also similar averaging at $8.6 \%$, which was substantially lower than the $28 \%$ for oats fuels. In terms of lignin, the five vegetation fuel types fell into three distinct groupings. The oats fuel at $7.8 \%$ had the lowest lignin concentration, the three hardwoods with an average of $26 \%$ were intermediate and the softwood fuel, with a lignin concentration nearly six times that of oats, had the highest level $(44.5 \%)$

\subsection{Fuel lignin composition}

The lignin pyrolysis products of fuels from the Py GC-MS analysis are shown in Table 2. All the angiosperm fuels (the three hardwoods and wild oats) contained lignin pyrolysates from all three lignin units (Table 2). As expected, the pine fuel contained no syringyl products. For the pine and oat fuels, $70-80 \%$ of the total lignin products pyrogram peak area was 
contributed by guaiacyl derivatives. For the hardwood fuels, $\geq 80 \%$ of the lignin pyrolysis products were syringyl and guaiacyl phenols.

Of the $p$-hydroxyphenyl derivatives, phenol and the three isomers of cresol were the dominant pyrolysis products (accounting for $75-87 \%$ of peak areas) irrespective of fuel type (Table 2). The balance was mainly made up by dimethylphenols and 4-ethylphenol. With respect to the guaiacyl lignin products, 4-vinylguaiacol was the single most abundant pryolysate in all the five fuel types, particularly in the wild oats and pine fuels. Other pyrolysates with high relative abundance included guaiacol, 4-methylguaiacol and 4ethylguaiacol, vanillin, cis-isoeugenol and acetovanillone (Table 2). For the angiosperm fuels, the relative abundances of the syringyl-derived pyrolysates were similar among the hardwood trees; however, in the wild oats, the relative abundances of the syringyl-derived products, except syringol, were consistently less than those of the hardwoods.

\subsection{Volatile phenols in smoke emissions}

Smoke emissions from pyrolysis of the five fuels during the vine smoke exposure experiment contained a range of lignin pyrolysates (Table 3). All five fuels had relatively high levels of the following $p$-hydroxyphenyl derivatives: phenol, $o$-, $p$ - and $m$-cresols, 4-ethylphenol and 2,4-dimethylphenol. Of the guaiacyl derivatives, the dominant compounds in the smoke emissions from each fuel were guaiacol, 4-methylguaiacol, 4-ethylguaiacol, eugenol and vanillin. By contrast, only syringol was the significant pyrolysate from the syringyl unit of lignin from each fuel type except the pine fuel which had no syringyl products in its smoke emissions. The smoke emissions from prescribed burns of marri-, karri-dominated forests as well as a wild oats pasture had similar lignin pryolysate profiles (Table 3) as those of the respective fuels during the vineyard experiment. 


\subsection{Putative smoke taint compounds in wines}

\subsubsection{Total (free and bound) lignin-derived putative smoke taint compounds in wines}

Wines from unsmoked, control, grapes contained relatively high background levels (311 $\mu \mathrm{g} / \mathrm{L}$ ) of total (free and bound) lignin degradation products (Table 4). Smoke exposure of vines $14 \mathrm{~d}$ after the onset of grape ripening significantly increased the total concentrations of lignin-derived compounds in wines. This increase was fuel type dependent and ranged from $74 \%$ in the karri smoke treatment to $146 \%$ in the wild oats smoke treatment (Table 4). Significant increases also occurred across all three lignin unit derivatives; however, the average magnitude of increases differed in the following order: guaiacyl derivatives $(362 \%)>$ $p$-hydroxyphenyl derivatives $(221 \%)>$ syringyl derivatives $(72 \%)$ (Table 4$)$. Irrespective of fuel type or smoke exposure, syringyl derivatives dominated the total pool of lignin-derived compounds, accounting for between 54 and 78\% (Table 4). The remainder was approximately equally apportioned between the $p$-hydroxyphenyl and guaiacyl groups of compounds in oat and pine smoke-affected wines, while in the control and hardwood smoke affected wines, the $p$-hydroxyphenyl derived compounds accounted for a consistently higher proportion than the guaiacyl derivatives.

The smoke-derived compounds in wines showed no correspondence with the lignin composition of the pyrolysed fuels. Thus, wines from grapes exposed to smoke of the pine fuel, the lignin of which contains no syringyl moieties or detectable syringyl derivatives in its smoke, unexpectedly contained high levels of syringyl products (Table 4). Indeed, smoke of gymnosperm and angiosperm fuels elicited equivalent levels of total syringyl derivatives in wines.

Of the $p$-hydroxyphenyl lignin derivatives, phenol, $o-, p-, m$-cresol and 4-ethylphenol were consistently present in both smoke affected and unaffected wines. However, in smoke affected wines all these compounds were significantly elevated (Table 4). While phenol was 
generally the single largest component of the $p$-hydroxyphenyl derivatives, the combined cresols (free and glycoside-bound $o^{-}, p-$, and $m$-cresol) dominated (67-75\%) the total $p$ hydroxyphenyl pool (Table 4).

Of the guaiacyl group, vanillin and acetovanillone were present at considerably higher total (glycoside-bound plus free) concentrations than any others. Nonetheless, the levels of these two compounds were independent of smoke exposure (Table 4). The guaiacyl derivatives that increased due to smoke exposure were guaiacol, 4-methylguaiacol, 4ethylguaiacol, 4-propylguaiacol and 4-vinylguaiacol (Table 6). Of the total pool of five guaiacyl derivatives that responded to smoke exposure, guaiacol was by far the largest (54$70 \%$ ) component with 4-methylguaiacol a distant second at 19-37\% contribution (Table 4).

Control wines contained moderately high, $241 \mu \mathrm{g} / \mathrm{L}$, total (volatile plus glycoconjugates) concentrations of the syringyl-derived compounds syringol, syringaldehyde and acetosyringone (Table 4). In smoke-affected wines, total concentrations of all these syringyl compounds including 4-methylsyringol were significantly elevated with the exception of syringaldehyde in pine or wild oats smoke affected wines (Table 4). Unexpectedly, wines made from grapes exposed to pine fuel smoke contained syringol and acetosyringone which, respectively, were 1.6 and 2.0 times the levels found in control wines (Table 4).

Some of the lignin pyrolysis products that were present in Py GC-MS (fuels) and/or TD GC-MS (smoke emissions) were either not detected or present below their detection limits in wines $(\sim 5 \mu \mathrm{g} / \mathrm{L})(c f$. Tables 2,3 and 4$)$.

\subsubsection{Effect of smoke exposure on glycoside-bound lignin derivatives in wine}

Averaged across fuel types, the total pool of glycoconjugated lignin derivatives was more than 2.8 times the levels found in control wines (Table 5). Once again, the largest response to smoke exposure occurred in the total concentration of the guaiacyl derivatives (4.3-fold) 
followed by $p$-hydroxyphenyl (3-fold) with the least responsive being the total of syringyl products (1.8-fold).

Control wines contained measurable levels (3.6 - $12.4 \mu \mathrm{g} / \mathrm{L})$ of glycoconjugates of phenol, $o$-cresol, $m$-cresol, $p$-cresol and 4-ethylphenol (Table 5). While no additional non-volatiles of $p$-hydroxyphenyl origin were detected in smoke affected wines, smoke exposure increased the concentrations of these five compounds by up to 8-fold (Table 5). The effects of fuel type and/or the smoke exposure treatments on the levels of the glycoside-bound $p$-hydroxyphenyl derivatives closely tracked the effects observed on the total (free- and glycoside-forms) $p$ hydroxyphenyl compounds ( $c f$. Table 4 and 5). Thus, karri smoke affected wines, while significantly different from the control wines, contained lower concentrations of each of the glycoside-bound $p$-hydroxyphenyl compounds than wines from grapes exposed to smoke from any of the other four fuels (Table 5). Similarly, regardless of fuel type or smoke exposure, the cresol isomers as a group dominated (56-60\%) the glycoside-bound pool of $p$ hydroxyphenyl derivatives (Table 5).

The total concentrations of glycoconjugated guaiacyl derivatives (guaiacol, 4methylguaiacol, 4-ethylguaiacol, 4-propylguaiacol and 4-vinylguaiacol) in smoke affected wines were 3 to 5.5 times the level in unsmoked, control wines (Table 5). Of the fuel types, the pine and oat fuels yielded significantly higher total concentrations of glycoside-bound guaiacyl derivatives in wines than any of the hardwood fuels.

Generally, smoke exposure also significantly elevated individual glycoside-bound compounds of guaiacyl lignin origin. Quantitatively, however, guaiacol and 4-methylguaiacol were the dominant components, respectively accounting for $56-69 \%$ and $20-38 \%$ of the total glycoside-bound guaiacyl derived compounds in smoke affected wines. Interestingly, the bound 4-methylguaiacol levels of wines from pine smoke exposed grapes were 1.9 times those from the wines affected by the other fuel types. In control wines, glycoside-conjugates 
of 4-ethylguaiacol, 4-propylguaiacol and 4-vinylguaiacol were below quantitation limits as was 4-propylguaiacol from the jarrah treatment.

Control wines contained substantial background levels $(72 \mu \mathrm{g} / \mathrm{L})$ of total glycoconjugates of syringyl compounds (Table 5). Smoke exposure further raised the already high background concentrations, depending on vegetation fuel type, by 22-124\% (Table 5). However, syringol was the only compound significantly elevated across all fuel types including the pine fuel. Whilst exposure of grapes to smoke of the gymnosperm fuel, compared to the control, significantly increased the syringol concentration in wines (26.5 vs $9.8 \mu \mathrm{g} / \mathrm{L})$, the effect of the gymnosperm fuel smoke was less than the effect of smoke from the angiosperm fuels, i.e. hardwoods and wild oats (Table 5). Interestingly, no glycoside-bound 4-methylsyringol was detected $(<1.5 \mu \mathrm{g} / \mathrm{L})$ in any of the wines.

Syringaldehyde and acetosyringone were the other glycoside-bound syringyl-derivatives affected by smoke. In particular, while wines from the control, pine or wild oats treatments contained comparable levels of these compounds, smoke from the hardwood fuels significantly elevated concentrations of glycoside-bound syringaldehyde and acetosyringone in wines (Table 5).

\subsubsection{Effect of smoke exposure on free phenols in wine}

The total level of volatile lignin derivatives in smoke affected wines was, on average, nearly double the levels found in control wines (Table 6). Smoke exposure also significantly increased the total concentrations of volatiles in each of the three lignin types. However, the relative responses were different. Relative to the respective levels in control wines, the volatile guaiacyl derivatives were the most responsive to smoke exposure ( 6.5 times), followed by the total of $p$-hydroxyphenyl products $(\sim 5$-fold $)$ while the syringyl derivatives 
were the least responsive (1.7 times) reflecting the high background level of syringyl derivatives in wines. However, irrespective of smoke exposure, the syringyl derivatives were the dominant (77-94\%) components of the total pool of volatile phenols in the wines (Table 6). The remainder of the total volatile phenols pool was approximately equally contributed by the $p$-hydroxyphenyl and guaiacyl derivatives.

Of the volatiles of the $p$-hydroxyphenyl derivatives, while phenol was the single largest (32-38\%) component in wines from smoke exposed grapes, regardless of smoke exposure, the cresols as a group once again dominated (50-70\%) the total of free $p$-hydroxyphenyl derivatives (Table 6). Of the free guaiacyl derivatives, only guaiacol and 4-methylguaiacol were consistently found in quantifiable levels regardless of smoke exposure. As expected, however, the concentrations of these analytes were significantly higher in wines from smoke exposed grapes than from control grapes (Table 6). The other guaiacyl lignin derivatives (4ethylguaiacol, 4-propylguaiacol and 4-vinylguaiacol) were present at trace levels. Thus, free guaiacol and 4-methylguaiacol were the dominant volatile components, jointly accounting for $82-100 \%$ of the total pool of guaiacyl derivatives, as was the case with the glycoside-bound forms ( $c f$. Table 5 and Table 6).

Control wines contained substantial levels of volatile syringol and acetosyringone (72 and $97 \mu \mathrm{g} / \mathrm{L}$, respectively). Smoke exposure, regardless of fuel type, significantly increased the levels of these compounds (Table 6). 4-methylsyringol was not detected in control wines but was present at low levels in all wines made from grapes exposed to smoke. Although all wines, irrespective of smoke exposure, had moderate levels $(\geq 48 \mu \mathrm{g} / \mathrm{L})$ of glycoside-bound syringaldehyde, 19 months after bottling, no free syringaldehyde was detected $(<3 \mu \mathrm{g} / \mathrm{L})$ in any of the wines. 
Smoke exposure also significantly increased (depending on fuel type by $37-88 \%$ ) the total concentrations of the free syringyl derivatives. Regardless of smoke exposure, $>96 \%$ of the total free pool of syringyl derivatives in wines was contributed by acetosyringone (53-65\%) and syringol (33-46\%). Surprisingly, the wines from vines exposed to pine fuel smoke, showed the highest concentration of total free syringyl derivatives $(318 \mu \mathrm{g} / \mathrm{L})$.

\subsubsection{Distribution of the lignin-derived compounds between the free and glycoside-bound} pools

In all wines, after 19 months of bottle storage, both the $p$-hydroxyphenyl and guaiacyl derivatives were predominantly present as glycoconjugates (Fig. 1), with the free volatile components of each group accounting for less than $30 \%$ of the total pools. By contrast, most $(61-78 \%)$ of the syringyl derivatives were present in free forms (Fig. 1). Nonetheless, even after 19 months, some syringyl derivatives such as syringaldehyde were detected only in the bound form.

\subsubsection{Influence of canopy size on accretion of lignin pyrolysis products in wine}

The concentrations of several of the lignin pyrolysis products in wines from smoke exposed grapes showed consistent negative correlations with vine leaf area as well as with leaf area per bunch (Fig. 2).

\section{Discussion}

\subsection{Fuel and smoke composition}

In this study taxonomically distinct groups of vegetation fuels with different lignin composition were used to generate smoke, under conditions that reproduce bushfire pyrolysis temperature profiles, for fumigating grapevines at the start of grape ripening. The primary 
aim was to examine influence of the lignin makeup of vegetation on lignin pyrolysis products (potential smoke taint compounds) that accrue in wine as a result of exposure of grapes to smoke so generated. In a bushfire event, all components of vegetation, including partially decomposed litter from the soil surface, contribute to the resulting smoke. Each of the fuels used here was thus compiled in proportion to components of the respective vegetation fuel types that are pyrolysed during a decadal bushfire event - the typical forest fire management burn cycle in the studied wine region. In fuels such as these that comprise variously decomposed components, it is pertinent that the fuels retain compositional variation characteristic of the vegetation types used. In this respect, the lignocellulose analyses results were broadly consistent with the expected composition of these vegetation types (Lebo et al., 2001). Nonetheless, the radiata pine fuel had a higher lignin concentration than was expected. This was due to the high (90\%) contribution of needles, which have lignin concentration in the range of $37 \%$ (in freshly senesced needles) to $>50 \%$ (in old, partially decomposed needles) (Girisha et al., 2003).

A further detailed analysis of the lignin composition of the five fuel types indicated that while the angiosperms (hardwood trees and wild oats fuels) contained lignin pyrolysis products from all three lignin units, the dominant components were the guaiacyl derivatives in wild oats, and the syringyl followed by guaiacyl compounds in hardwoods. Guaiacol and substituted guaiacols were the principal components of pine fuel lignin; however it contained no syringyl derivatives as expected for a gymnosperm specimen (Kjällstrand et al., 2000; Nolte et al., 2001; Greenwood et al., 2002; Pettersen, 1984) although trace levels are sometimes reported (Kristensen et al., 2009) in spite of the general absence of the requisite syringyl lignin biosynthetic enzymes in gymnosperms (Weng \& Chapple, 2010). On the whole, despite the inclusion of partially degraded components in the fuel samples, the relative proportions of the lignin derivatives were still distinct enough to characterise the fuels into 
the three lignin types (grass, hardwood and softwood) (Higuchi, 1990; Pettersen, 1984; Buranov \& Mazza, 2008) (Table 2, supplementary Fig. S2a, b).

Smoke emissions from the vineyard smoke exposure experiment and the prescribed burns of three of the vegetation types contained phenol, guaiacol and several of their substituted forms as well as syringol and trace levels of 4-methylsyringol. Emissions from the radiata pine fuel contained no syringyl derivatives consistent with the Py GC-MS results presented here and with earlier reports that members of the gymnosperm taxa lack syringyl lignin (Kjällstrand et al., 2000; Nolte et al., 2001; Schauer et al., 2001; Bari et al., 2009) although some exceptions have been noted (e.g., Fine et al. 2001). While these results confirm that most of the volatile lignin degradation products that accrue in wines are present in smoke emissions, the results from the pine fuel, as discussed below, exemplify an exception to this generalisation. Volatile phenols emission profiles from the prescribed burns and from smoke generated during the vineyard experiment were broadly similar, indicating that (1) the pyrolysis conditions during the vineyard smoke exposure successfully simulated bushfire/prescribed burn conditions, and (2) as a result, the vines and grapes were exposed to the types of volatile phenols that would occur in bushfire and/or prescribed burn smoke. Although the emissions profiles of volatile phenols from the prescribed burns and vineyard experiment were similar in this study ( $c f$., Table 2 and 3), the relative abundances, especially of syringyl and guaiacyl derivatives, were lower than those reported from prescribed burn emissions in the Adelaide Hills, South Australia (Hayasaka et al., 2010a). However, in the latter case, sampling was carried out in winter when conditions are likely to favour smouldering, which increases the yield of these methoxyphenols (Kjällstrand et al., 2000).

\subsection{Putative smoke taint compounds in wine}


Much of the earlier work into smoke taint in wines focussed on accretion of guaiacyl lignin derivatives (Kennison et al., 2007; 2008; Sheppard et al., 2009; Singh et al., 2011). The results from this study demonstrate that wines made from smoke exposed grapes, compared to controls, can accrue significantly elevated levels of other phenols (Tables 4-6) that are emitted in smoke during pyrolysis of lignin (Table 3). This effect was generally invariant of the vegetation source of smoke. More recently, Hayasaka et al. (2010a) also reported increased accumulation of phenol, syringol and their substituted forms in bushfire affected wines. However, in this controlled smoke exposure experiment, as in our study of wines made from grapes exposed to wildfire generated smoke (Singh et al., in Press), a broader range of lignin pyrolysis products are identified than has been reported hitherto. This is indicative of the possibility that more compounds may contribute to smoke taint aroma of smoke affected wines than the few volatile phenols implicated to date. This is consistent with the suggestion that sensory descriptors of smoke affected wines are varied and more complex than those imparted by the commonly used smoke taint marker compounds, guaiacol and 4methylguaiacol (Kennison et al., 2007; Hayasaka et al., 2010a).

This study also revealed that while the levels of the commonly reported smoke taint markers, guaiacol and 4-methyl guaiacol, were certainly the dominant components of the guaiacyl lignin derived compounds, these represented only about $20 \%$ of the total pool of lignin derived putative smoke taint compounds in wines. Instead, the quantitatively dominant contributors (> 50\%) were pyrolysis products of syringyl lignin, while phenol and substituted phenols were of broadly comparable abundance as guaiacol and substituted guaiacols (Table 4). Comparable proportions have been found in wines of several varieties exposed to wildfire smoke (Singh et al., in Press). However, some perspective is warranted on relative contributions of different phenol groups to the total pool. Firstly, the quantitative relative abundance of putative taint compounds does not necessarily indicate the respective 
compound's taint impact owing to differences in aroma and/or taste perception threshold concentrations. Thus, for example, while syringol was present at a far higher level than guaiacol (101 vs. $19 \mu \mathrm{g} / \mathrm{L}$ ), its perception threshold concentration is also high (for example, in red wine $570 v s .75 \mu \mathrm{g} / \mathrm{L}$, cited in Petruzzi et al., 2010). Yet, in grapes exposed to high density bushfire smoke for an extended period, the total pool of syringol and substituted syringols can reach 25 times $(\sim 10 \mathrm{ppm})$ the levels found in this limited duration smoke exposure experiment (Singh et al., in Press), and hence can far exceed their apparent high perception threshold. Secondly, the comparison above, of guaiacols $v s$. syringols, may be slightly skewed towards the latter. Here, the total of each of these compounds was estimated from the sum of the volatiles released during fermentation and those released from acid hydrolysis of the glycoside-bound phenols. According to Hayasaka et al. (2010a), however, yields of phenol, guaiacol and their substituted forms from acid hydrolysis of the respective glycoconjugates are considerably less $(<10 \%)$ than that of glycoside-bound syringol and 4methylsyringol (33\%).

Wines made from smoke unexposed grapes (control treatment) contained a high total (241 $\mu \mathrm{g} / \mathrm{L})$ of endogenous volatile and glycoside-bound syringyl products. Given that grapevine lignin contains syringyl derivatives archetypal of a woody angiosperm (Guillén \& Ibargoitia, 1996) and that grape juice was fermented on skins (thus facilitating hydrolytic release of lignin units into wine (Loscos et al., 2009)), the presence of syringyl derivatives, albeit at high levels, is plausible (see also Singh et al., in Press). The observed significant increases in the concentrations of total syringols and substituted syringols in wines impacted by smoke of the angiosperm fuels (the three hardwoods and wild oat) may be attributable to exogenous uptake due to the presence of syringyl derivatives in fuels (Table 2) and more significantly in their smoke emissions (Table 3). The provenance for the elevated levels of syringols in wines from pine smoke exposed grapes (Table 4-6) however cannot be similarly attributed since 
syringyl derivatives were expectedly lacking in this fuel and its smoke emissions. During smoke exposure of vines/grapes due care was taken to avoid smoke cross contamination from smoke of the angiosperm fuels. At any rate, if contamination was a mechanism, the control wines would have comparable levels to the pine smoke impacted wines. A further experiment is underway to understand the mechanism for the observed increase in syringyl products in wines from pine smoke exposed grapes.

\subsection{Relative abundances of free and bound phenols in wine}

Nineteen months after bottling, the distribution of putative smoke taint compounds in wines between glycoside-bound and volatile pools differed according to lignin class. Regardless of the applied smoke treatments, pyrolysates of $p$-hydroxyphenyl and guaiacyl origin were predominantly (72-87\%) present as glycoconjugates, with free forms making up the balance. By contrast, syringol and substituted syringols released after acid hydrolysis made up $<40 \%$ of the total pool of syringyl derivatives in wines (Fig. 1). The predominance of glycosidebound phenol, guaiacol and their substituted forms over the volatile forms is broadly consistent with previous findings (Singh et al., 2011; Hayasaka et al., 2010a, c; Wilkinson et al., 2011). The results for the syringyl derivatives, however, contrasts with those reported in Hayasaka et al. (2010a) who found that levels of volatile syringol and 4-methylsyringol in both red and white wines were $<4 \%$ of the total pool (i.e., total of volatiles after acid hydrolysis) for each of these compounds. The reason for this disparity is not clear. However, the wines in this study, unlike those of Hayasaka et al. (2010a), were analysed 19 months after bottling, the typical red wine maturation duration. The relatively long storage under the mildly acidic environment of wines coupled with syringols possibly having a weak glycoside bond (Hayasaka et al., 2010a) may have facilitated slow release of syringol and substituted syringols from their glycosides thus tilting the balance in favour of the free forms. Regardless 
of the mechanism, however, the observation that 19 months after bottling more than $70 \%$ of the phenol, guaiacol and their substituted forms exist as glycoconjugates presents a significant practical problem in smoke taint management. It also presents a challenge for efforts to remove volatile smoke taint compounds from wines through reverse osmosis filtration (Fudge et al., 2011) since the major "taint" reservoir (glycoconjugates) still remains in wines.

\subsection{Influences of vine canopy size and type of lignin pyrolysed on concentrations of putative} smoke taint in wine

In nearly all of the lignin pyrolysis products, the concentrations of phenols in wines were negatively correlated to vine canopy leaf area as well as the leaf area per bunch (Fig. 2). The mechanism of accretion of smoke borne lignin pyrolysates in berries is not well understood. Some of the possibilities include direct uptake of lignin products in smoke emissions by berries and/or foliar uptake and subsequent translocation and sequestration in berries. Tracer studies have shown leaves and/or berries take up phenols (Beattie \& Seibel, 2007; Hayasaka et al., 2010b), although only trace quantities are subsequently translocated to berries (Hayasaka et al., 2010b). If the mechanism of uptake in berries was primarily through the leaves, then a positive relationship between canopy size (absorptive surface area) and taint concentration would be expected instead of the inverse relationship found in the current study. This suggests that direct uptake by berries may be a significant contributor to accumulation of phenols in berries. Phenol, guaiacol, syringol and their substituted forms from lignin pyrolysis are emitted in gas phase and particle phase, and particularly for some of the syringyl derivatives such as acetosyringone (Schauer et al., 2001). While canopy area may have minimal effect on uptake of emissions from gas phase, a denser canopy can intercept particulate phase emissions, and thus reduce contact with the surface of berries. The 
negative relationship we observed between leaf area per bunch and concentration of phenols (i.e., the more the grapes are sheltered by foliage the less the "taint" concentration) is consistent with this explanation. Furthermore, the correlation was stronger for acetosyringone whose relative emission in particle phase is high compared to other lignin pyrolysis emissions (Schauer et al., 2001).

The vegetation fuels used in this study were chosen to investigate links between the pyrolysis of different lignin sources and the appearance of putative smoke taint compounds in wines. The results, particularly of wines from the pine smoke treatment, have revealed that the lignin pyrolysis products that accrue in wines do not necessarily discern the lignin composition of the pyrolysed fuel. Further work is needed to address marker compound(s) based apportionment or attribution of vegetation-type source of smoke taint.

\section{Conclusions}

In this study vegetation fuels with varying lignin makeup were used to generate smoke and fumigate vines at the start of berry ripening. The aim was to examine whether putative smoke taint compounds that accumulate in wines following exposure of grapes to a bushfire event reflect the lignin composition of vegetation that is pyrolysed. The results showed a broader range of lignin pyrolysis products in wines than have been reported to date, suggesting more compounds are likely to contribute to the perceived smoke taint than have been implicated. The effect of vegetation fuel types was less about changes in the identity of compounds than their quantities. Thus, and more significantly, fuel lignin makeup does not appear to be a good indicator of the types of lignin pyrolysis products that become elevated in wines. This is predicated on the finding that radiata pine fuel which did not contain syringyl units in its lignin nor pyrolysis products of syringyl units in its smoke emission gave rise to significantly elevated levels of syringols and substituted syringols in wines made from grapes exposed to 
pine smoke. The mechanism for this observation is not clear, but further work is underway to better understand this response.

This work also demonstrated that several phenols other than guaiacyl products (i.e. guaiacol and 4-methylguaiacol, the routinely used smoke "taint" measures) are present in wines at similar or higher concentrations than the guaiacyl phenols. Significant among these are the $p$-hydroxyphenyl lignin degradation products (phenol, $o-, m-$, and $p$-cresol) and

syringol. The cumulative levels of these "other" phenols are considerably higher than those of the guaiacols. Since smoke tainted wines have sensory characteristics beyond those that could be attributed to guaiacols, the $p$-hydroxyphenyl products and syringols, which become elevated following smoke exposure, are possible candidates to account for the additional smoke taint characteristics in wines.

\section{Acknowledgements}

We would like to thank Dr. Lachie $\mathrm{M}^{\mathrm{c}} \mathrm{Caw}$, Drew Haswell and Rick Sneeuwjagt of the Western Australian Department of Environment and Conservation for their expert advice, the Shire of Augusta Margaret River for the use of their fire fighting resources, Xanadu Wines for allowing us to conduct trials in their vineyard, Geoff Chidlow for technical support in GC-MS analysis and John Alferink and the Wallcliffe Bushfire Brigade for providing their technical expertise, resources and manpower for fire safety at controlled burns and vineyard trials. The work reported here was supported in part by the Australian grape growers and wine makers through their investment body, the Grape and Wine Research and Development Corporation. DPS and MOD would like to thank the Victorian Department of Primary Industries for funding their work through "The Centre for Expertise in Smoke Taint Research". 


\section{References}

Bari, M.A., Baumbach, G., Kuch, B. \& Scheffknecht, G. (2009). Wood smoke as a source of particle-phase organic compounds in residential areas. Atmospheric Environment, 43, $4722-4732$.

Bates, M., Bruno, P., Caputi, M., Caselli, M., De Gennaro, G. \& Tutino, M. (2008). Analysis of polycyclic aromatic hydrocarbons (PAHs) in airborne particles by direct sample introduction thermal desorption GC/MS. Atmospheric Environment, 42, 6144-6151.

Beattie, G. A. \& Seibel, J. R. (2007). Uptake and localization of gaseous phenol and p-cresol in plant leaves. Chemosphere, 78, 528-537.

Browne, F.L. (1958). Theories of the combustion of wood and its control. The USDA-Forest Service Forest Products Laboratory Report No. 2136. Madison, WI, USA.

Buranov, A.U., \& Mazza, G. (2008). Lignin in straw of herbaceous crops. Industrial Crops and Products, 28, 237-259.

Burrows, N.D. (1994). Experimental development of a fire management model for jarrah (Eucalyptus marginata ex Sm.) forest. PhD Thesis. Canberra: The Australian National University.

Butt, D. (2006). Thermochemical processing of agroforestry biomass for furans, phenols, cellulose and essential oils. Rural Industries Research and Development Corporation Pub. No. 06/121. ACT, Australia.

Duchesne, L.C., \& Wetzel, S. (1999). Effect of clear-cutting, prescribed burning and scarification on litter decomposition in an eastern Ontario Jack Pine (Pinus banksiana) ecosystem. International Journal of Wildland Fire, 9, 195-201.

Dungey, K.A., Hayasaka, Y., \& Wilkinson, K.L. (2011). Quantitative analysis of glycoconjugate precursors of guaiacol in smoke-affected grapes using liquid 
chromatography-tandem mass spectrometry based stable isotope dilution analysis. Food Chemistry, 126, 801-806.

Faix, O., Bremer, J., Schmidit, O., \& Stevanovic, T. (1991). Monitoring of chemical changes in white-rot degraded beech wood by pyrolysis-gas chromatography and Fourier transform infrared spectroscopy. Journal of Analytical and Applied Pyrolysis, 21, 147162.

Fahmi, R., Bridgwater, A.V., Thain, S., \& Donnison, I. (2007). Prediction of Klason lignin and lignin thermal degradation products by Py-GC/MS in a collection of Lolium and Festuca grasses. Journal of Analytical and Applied Pyrolysis, 80, 16-23.

Fine, P.M., Cass, G.R., \& Simoneit, B.R.T. (2001). Chemical Characterization of Fine Particle Emissions from Fireplace Combustion of Woods Grown in the Northeastern United States. Environmental Science and Technology, 35, 2665-2675.

Fudge, A.L., Ristic, R., Wollan, D., \& Wilkinson, K.L. (2011). Amelioration of smoke taint in wine by reverse osmosis and solid phase adsorption. Australian Journal of Grape and Wine Research, 17, S41-S48.

Gilbert, J., \& Knowles, M. E. (1975). The chemistry of smoked foods: a review. Journal of Food Technology, 10, 245-261.

Girisha, G.K., Condron, L.M., Clinton, P.W., \& Davis, M.R. (2003). Decomposition and nutrient dynamics of green and freshly fallen radiata pine (Pinus radiata) needles. Forest Ecology and Management, 179, 169-181.

Gould, J.S., McCaw, W.L., Cheney, N.P., Ellis, P.F., Knight, I.K., \& Sullivan, A.L. (2007). Project Vesta: Fire in dry Eucalypt forest: Fuel structure, fuel dynamics and fire behaviour, report to Ensis-CSIRO and Department of Environment and Conservation (Australian Government Printing Service, Canberra ACT). 
Greenwood, P. F., van Heemst, J. D. H., Guthrie, E. A., \& Atcher, P. G. (2002). Laser micropyrolysis GC-MS of lignin. Journal of Analytical and Applied Pyrolysis, 62, 365373.

Guille'n, M. D., \& Ibargoitia, M. L. (1996). Relationships between the maximum temperature reached in the smoke generation processes from Vitis vinifera L. Shoot sawdust and composition of the aqueous smoke flavoring preparations obtained. Journal of Agricultural and Food Chemistry, 44, 1302-1307.

Hayasaka, Y., Baldock, G.A., Parker, M., Pardon, K.H., Black, C.A., Herderich M.J., \& Jeffery, D.W. (2010a). Glycosylation of smoke-derived volatile phenols in grapes as a consequence of grapevine exposure to bushfire smoke. Journal of Agricultural and Food Chemistry, 58, 10989-10998.

Hayasaka, Y., Baldock, G.A., Pardon, K.H., Jeffery, D.W., \& Herderich, M.J. (2010b). Investigation into the formation of guaiacol conjugates in berries and leaves of grapevine Vitis Vinifera L. Cv. Cabernet Sauvignon using stable isotope tracers combined with HPLC-MS and MS/MS Analysis. Journal of Agricultural and Food Chemistry, 58, 20762081

Hayasaka, Y., Dungey, K.A., Baldock, G.A., Kennison, K.R., \& Wilkinson, K.L. (2010c). Identification of a $\beta$-D-glucopyranoside precursor to guaiacol in grape juice following grapevine exposure to smoke. Analytica Chimica Acta, 660, 143-148.

Higuchi, T. (1990). Lignin biochemistry: Biosynthesis and biodegradation. Wood Science and Technology, 24, 23-63.

Jones, G.V., White, M.A., Cooper, O.R., \& Storchmann, K. (2005). Climate Change and Global Wine Quality. Climate Change, 73, 319-343

Keeley, J.E., Pausas, J.G., Rundel, P.W., Bond, W.J., \& Bradstock,R.A. (2011). Fire as an evolutionary pressure shaping plant traits. Trends in Plant Science, 16, 406-411. 
Kennison, K.R., Wilkinson, K.L., Williams, H.G., Smith, J.H., \& Gibberd, M.R. (2007). Smoke-derived taint in wine: Effect of post-harvest smoke exposure of grapes on the chemical composition and sensory characteristics of wine. Journal of Agricultural Food Chemistry, 55, 10897-10901.

Kennison, K.R., Gibberd, M.R., Pollnitz, A.P., \& Wilkinson, K.L. (2008). Smoke-Derived taint in wine: The Release of Smoke-Derived Volatile Phenols during Fermentation of Merlot Juice following Grapevine Exposure to Smoke. Journal of Agricultural Food Chemistry, 56, 7379-7383.

Kjallstrand, J., Ramnas, O., \& Petersson, G. (2000). Methoxyphenols from burning of Scandinavian forest plant materials. Chemosphere, 41, 735-741.

Kristensen, R., Coulson, S., \& Gordon, A. (2009). THM PyGC-MS of wood fragment and vegetable fibre forensic samples. Journal of Analytical and Applied Pyrolysis, 86, 90-98.

Lebo Jr., S.E., Gargulak, J.D., \& McNally, T.J. (2001). Lignin. Kirk-Othmer Encyclopaedia of Chemical Technology, Vol. 15 (pp. 1-32). New York: John Wiley \& Sons Inc.

Loscos, N., Hernandez-Orte, P., Cacho, J., \& Ferreira, V. (2009). Comparison of the suitability of different hydrolytic strategies to predict aroma potential of different grape varieties. Journal of Agricultural and Food Chemistry, 57, 2468-2480.

Nolte, C.G., Schauer, J.J., Cass, G.R., \& Simoneit, B.R.T. (2001). Highly Polar Organic Compounds Present in Wood Smoke and in the Ambient Atmosphere. Environmental Science and Technology, 35, 1912-1919.

Petruzzi, L., Bevilacqua, A., Ciccarone, C., Gambacorta, G., Irlante, G., Pati, S., \& Sinigaglia, M. (2010). Preliminary investigation on the use of microfungi in the treatment of oak chips: possible effects on wine. Journal of the Science of Food and Agriculture, 90, 2617-2626. 
Pettersen, R.C. (1984). The chemical composition of wood: The chemistry of solid wood. In R.M. Rowell (Ed.), Advances in chemistry series 207 (pp. 57-126). Washington, D.C.: American Chemical Society.

Ralph, J., \& Hatfield, R. D. (1991). Pyrolysis-GC-MS characterization of forage materials. Journal of Agricultural and Food Chemistry, 39, 1426-1437.

Rencoret, J., Gutiérrez, A., Nieto, L., Jiménez-Barbero, J., Faulds, C.B., Kim, H., Ralph, J., Martínez, Á., \& del Río, J.C. (2011). Lignin composition and structure in young versus adult Eucalyptus globulus plants. Plant Physiology, 155, 667-682.

Schauer, J.J., Kleeman, M.J., Cass, G.R., \& Simoneit, B.R.T. (2001). Measurement of emissions from air pollution sources. $\mathrm{C}_{1}-\mathrm{C}_{29}$ organic compounds from fireplace combustion of wood. Environmental Science and Technology, 35, 1716-1728.

Schmidt, O. (2006). Wood and tree fungi. Berlin: Springer-Verlag.

Sheppard, S.I., Dhesi, M.K., \& Eggers, N.J. (2009). Effect of pre- and post veraison smoke exposure on guaiacol and 4-methylguaiacol concentration in mature grapes. American Journal of Enology and Viticulture, 60, 98-103.

Simon, R., de la Calle, B., Palme, S., Meier, D., \& Anklam, E. (2005). Composition and analysis of liquid smoke flavouring primary products. Journal of Separation Science, 28, 871-882.

Singh, D.P., Chong, H.H., Pitt, K.M., Cleary, M., Dokoozlian, N.K., \& Downey, M.O. (2011). Guaiacol and 4-methylguaiacol accumulate in wines made from smoke-affected fruit because of hydrolysis of their conjugates. Australian Journal of Grape and Wine Research, 17, S13-S21

Singh, D.P., Zerihun, A., Kelly, D., Cain, N.M., Nankervis, P., \& Downey, M.O. A GC-MS based analytical method for detection of smoke taint associated phenols in smoke affected wines. Current Bioactive Compounds (In Press). 
Toth, L., \& Potthast, K. (1984). Chemical aspects of the smoking of meat and meat products. Journal of Food Research, 29, 87-158.

Vane, C.A., Drage, T.C., Snape, C.E., Stephenson, M.H., \& Foster, C. (2005). Decay of cultivated apricot wood (Prunus armeniaca) by the ascomycete Hypocrea sulphurea using solid state ${ }^{13} \mathrm{C}$ NMR and off-line TMAH thermochemolysis with GC-MS. International Biodeterioration and Biodegradation, 55, 175-185.

van Soest P. J., \& Wine R. H. (1967). Use of detergents in the analysis of fibrous feeds. (IV). Determination of plant cell-wall constituents. Journal of the Association of Official Analytical Chemists, 50, 50-55.

Vitzthum von Eckstaedt C., Grice, K., Ioppolo_Armanios M., Chidlow G., \& Jones M. (2011). $\delta \mathrm{D}$ and $\delta^{13} \mathrm{C}$ analyses of atmospheric volatile organic compounds by thermal desorption gas chromatography isotopme ratio mass spectrometry, Journal of Chromatography A, 1218, 6511-6517.

Weng, J.K., \& Chapple, C. (2010). The origin and evolution of lignin biosynthesis. New Phytologist, 187, 273-285.

Whiting, J., \& Krstic, M. (2007). Understanding the sensitivity to timing and management options to mitigate the negative impacts of bush fire smoke on grape and wine quality Scoping study. Department of Primary Industries: Melbourne, Victoria, Australia. MIS No. 06958 and CMI No 101284.

Wilkinson, K.L., Ristic, R., Pinchbeck, K.A., Fudge, A.L., Singh, D.P., Pitt, K.M., Downey, M.O., Baldock, G.A., Hayasaka, Y., Parker, M., \& Herderich, M.J. (2011). Comparison of methods for the analysis of smoke related phenols and their conjugates in grapes and wine. Australian Journal of Grape and Wine Research, 17, S22-S28.

Wittkowski, R., Ruther, J., Drinda, H., \& Rafiei-Taghanaki, F. (1992). Formation of smoke flavor compounds by thermal lignin degradation. In R. Teranashi, G.R. Takeora, \& M. 
Güntert (Eds.), Flavor precursors, ACS symposium series 490 (pp. 232-243). Washington

DC: American Chemical Society.

Yokoi H., Ishida Y., Ohtani H., Tsuge S., Sonoda T., \& Ona T. (1999). Characterization of within-tree variation of lignin components in Eucalyptus camaldulensis by pyrolysis-gas chromatography. Analyst, 124, 669-674.

Fig. 1. Distributions (\%) of the total putative smoke taint compounds pool between the free (solid slices) and glycoconjugate (hashed slices) components shown by lignin unit source and treatment. Treatment fuels are: C, unsmoked control; J, jarrah fuel; K, karri fuel; M, marri fuel; O, oat fuel; and $\mathrm{P}$, pine fuel.

Fig. 2. Correlations of totals of free and bound phenols with leaf area per vine (solid bar) and the leaf area per bunch (hashed bar). Data shown are for individual phenols as well as sums by lignin units. The dashed horizontal line denotes the critical value $(-0.394)$ at $p=0.05$, thus coefficients below -0.394 or above 0.394 are significant at $\mathrm{p}<0.05$.

Supplementary Fig. S1. Smoke sampling of a marri forest prescribed burn, May 2009. Smoke from prescribed burnings of marri and karri fuels were sampled during the Western Australian Department of Environment and Conservation's prescribed burn campaigns in May 2009 and May 2011, respectively. The marri block contained predominantly marri vegetation with shrub understory. The fire carried through with an approximate burn height of $5 \mathrm{~m}$ and only large logs and standing trees remained after the burn. The smoke samples from a prescribed burn of wild oats were collected in April 2010 from the same paddock which provided the wild oats fuel for the vine smoke exposure experiment. The paddock was ignited in the most upwind point and the fire was allowed to carry for thirty meters before sampling began. In the prescribed burning sampling events, the smoke laden air was drawn through at $200 \mathrm{ml} / \mathrm{min}$ using an SKC 222-3 personal air sampler (SKC, Eighty Four, Pennsylvania, USA). The sample pump was held in front of the flaming fire front for approximately $1 \mathrm{~min}$ before the fire front passed over the sample pump and TD tube held at a height of $1 \mathrm{~m}$. The total sample time for each prescribed burn was thirty minutes.

Supplementary Fig. S2. A) Canonical variate analysis of Py GC-MS data showing distinct grouping of fuels with respect to their lignin composition. Fuel types are: O, wild oats; P, pine; K, karri; J, jarrah; and M, marri. The circles around each fuel are the $95 \%$ confidence regions. Note that the fuels are grouped into three broadly different groups representing grass, pine and the three hardwood trees. B) cluster analysis of fuel lignin composition showing the fuels as falling into three distinct groups based on similarity of their lignin makeup. 


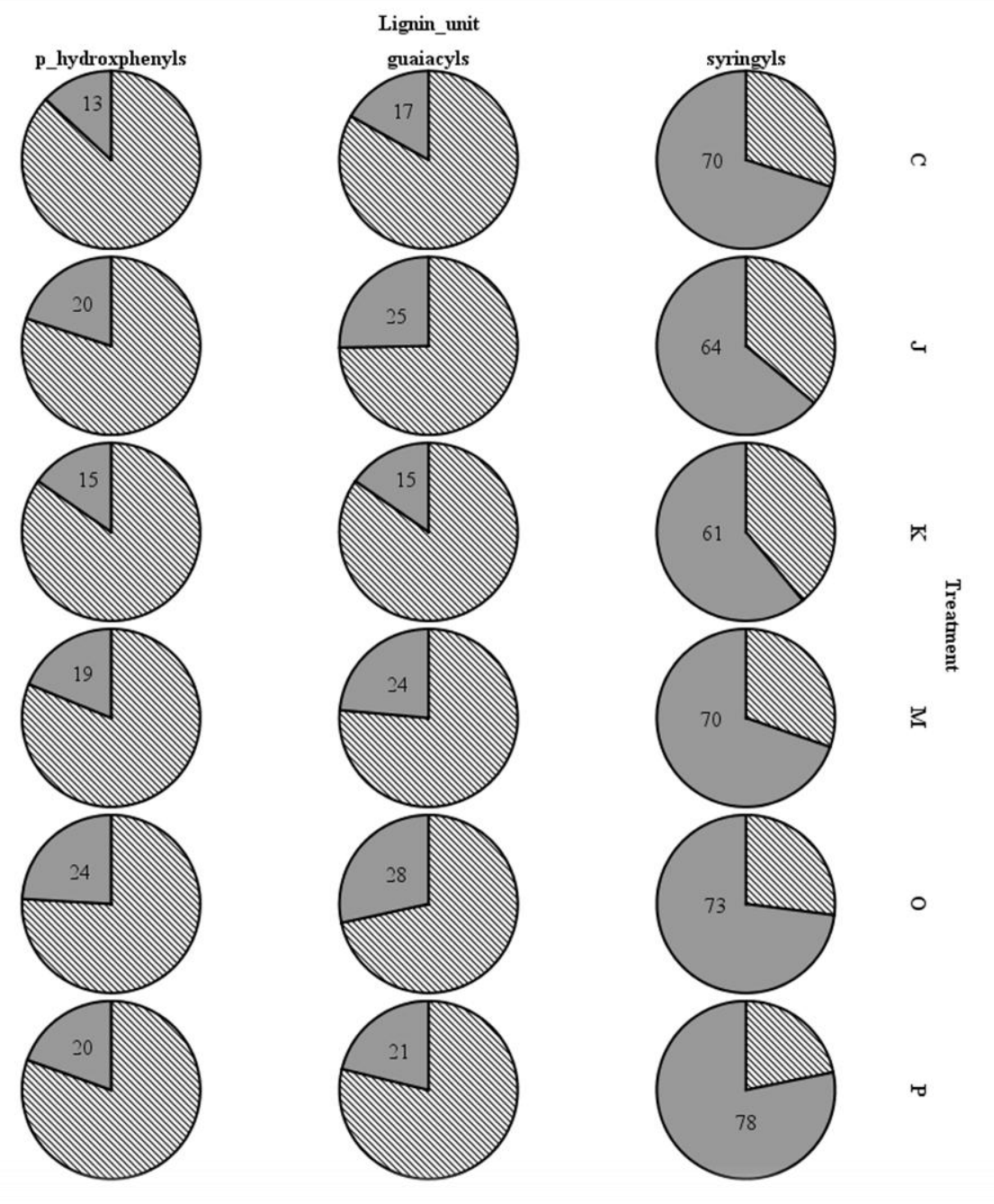

Fig. 1 


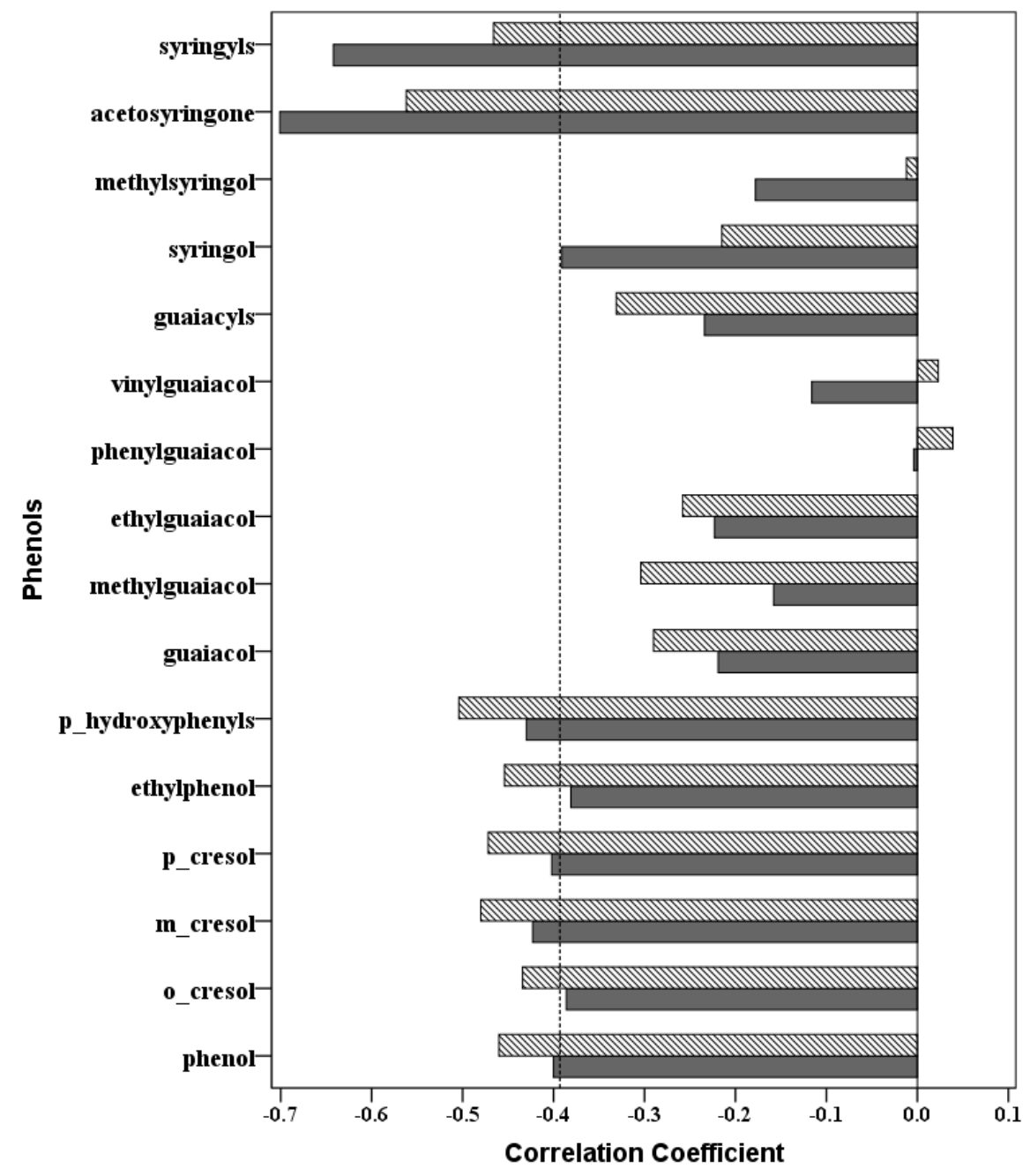

Fig. 2

Table 1. Lignocellulosic compositions of the fuels used for smoke generation. Data are mean \pm 1 s.e. $(n=3)$

\begin{tabular}{lccc}
\hline Fuel & Cellulose & Hemicellulose & Lignin \\
\hline Karri & $28.4 \pm 0.1$ & $8.1 \pm 0.2$ & $29.3 \pm 0.3$ \\
Jarrah & $24.2 \pm 0.4$ & $6.1 \pm 0.2$ & $23.5 \pm 0.1$ \\
Marri & $29.4 \pm 0.7$ & $9.0 \pm 0.2$ & $24.9 \pm 0.2$ \\
Pine & $23.7 \pm 0.4$ & $9.4 \pm 0.2$ & $44.5 \pm 0.4$ \\
Wild oats & $48.9 \pm 0.1$ & $28.0 \pm 0.3$ & $7.8 \pm 0.2$ \\
\hline
\end{tabular}


Table 2. Lignin composition of fuels based on Py GC-MS analysis. Fuel samples were analysed in triplicates; nq, not quantified.

\begin{tabular}{|c|c|c|c|c|c|c|}
\hline \multirow[t]{2}{*}{ Lignin unit } & \multirow[t]{2}{*}{ Lignin pyrolysates } & \multicolumn{5}{|c|}{$\begin{array}{l}\text { Relative abundance (\% of total lignin derived } \\
\text { pyrolysates) by fuel type }\end{array}$} \\
\hline & & Jarrah & Karri & Marri & Oats & Pine \\
\hline \multirow{8}{*}{$\begin{array}{l}p \text {-hydroxy- } \\
\text { phenyls }\end{array}$} & phenol & 5.9 & 8.7 & 3.4 & 4.6 & 6.8 \\
\hline & o-cresol & 2.4 & 1.7 & 0.8 & 1.1 & 3.2 \\
\hline & $m$ - and $p$ - cresol & 8.1 & 3.1 & 2.4 & 1.8 & 6.9 \\
\hline & 2,4-dimethylphenol & 1.2 & 0.8 & 0.5 & 0.3 & 1.8 \\
\hline & 4-ethylphenol & 2.4 & 1.2 & 1.0 & 1.1 & 2.3 \\
\hline & 4-hydroxybenzaldehyde & $\mathrm{nq}$ & $\mathrm{nq}$ & nq & 0.8 & $\mathrm{nq}$ \\
\hline & 4-allylphenol & $\mathrm{nq}$ & $\mathrm{nq}$ & $\mathrm{nq}$ & 0.5 & 0.8 \\
\hline & subtotal & $20.0 \pm 0.2$ & $15.5 \pm 0.6$ & $8.1 \pm 0.5$ & $10.2 \pm 0.2$ & $21.8 \pm 0.1$ \\
\hline \multirow{12}{*}{ guaiacyls } & guaiacol & 3.0 & 3.7 & 9.4 & 9.4 & 6.4 \\
\hline & 4-methylguaiacol & 3.6 & 4.9 & 4.2 & 3.1 & 11.9 \\
\hline & 4-ethylguaiacol & 4.1 & 1.4 & 0.9 & 3.1 & 3.1 \\
\hline & 4-vinylguaiacol & 14.0 & 10.2 & 12.7 & 41.3 & 26.9 \\
\hline & Eugenol & 1.0 & 0.8 & 1.0 & 1.3 & 2.6 \\
\hline & 4-propylguaiacol & nq & $\mathrm{nq}$ & nq & nq & 0.8 \\
\hline & Vanillin & 2.4 & 2.0 & 2.8 & 3.9 & 4.6 \\
\hline & trans isoeugenol & 1.2 & 1.3 & 1.2 & 0.4 & 1.9 \\
\hline & cis isoeugenol & 5.5 & 2.4 & 7.8 & 5.5 & 12.7 \\
\hline & homovanillyl alcohol & $\mathrm{nq}$ & nq & $\mathrm{nq}$ & 0.8 & $\mathrm{nq}$ \\
\hline & acetovanillone & 2.2 & 3.0 & 1.7 & 1.2 & 1.5 \\
\hline & homovanillic acid & 2.0 & 3.1 & $\mathrm{nq}$ & $\mathrm{nq}$ & 5.8 \\
\hline \multirow{11}{*}{ syringyls } & subtotal & $39.0 \pm 0.7$ & $32.8 \pm 0.6$ & $41.7 \pm 2.0$ & $70.0 \pm 0.6$ & $78.2 \pm 0.1$ \\
\hline & syringol & 8.0 & 6.6 & 5.0 & 6.7 & nd \\
\hline & 4-vinylsyringol & 11.6 & 15.2 & 18.6 & 4.7 & nd \\
\hline & 4-(2-propenyl) syringol & 1.8 & 2.4 & 3.0 & 0.8 & nd \\
\hline & Z-4-(1-propenyl)-syringol & 1.8 & 1.7 & 1.7 & 0.5 & nd \\
\hline & syringaldehyde & 4.0 & 5.2 & 4.1 & 1.2 & nd \\
\hline & E-4-(1-propenyl)-syringol & 10.4 & 14.3 & 15.1 & 3.1 & nd \\
\hline & acetosyringone & 3.4 & 6.3 & 2.7 & 2.4 & nd \\
\hline & $\begin{array}{l}3,5 \text {-dimethoxy-4- } \\
\text { hydroxycinnamaldehyde }\end{array}$ & $\mathrm{nq}$ & $\mathrm{nq}$ & $\mathrm{nq}$ & 0.4 & nd \\
\hline & subtotal & $41.0 \pm 0.9$ & $51.7 \pm 0.9$ & $50.2 \pm 0.9$ & $19.8 \pm 0.6$ & - \\
\hline & Total & 100.0 & 100.0 & 100.0 & 100.0 & 100.0 \\
\hline
\end{tabular}


Table 3. Volatile phenols in smoke emissions based on TD GC-MS analysis. Data are based on triplicate sample analyses; nd, not detected, nq, not quantified.

\begin{tabular}{|c|c|c|c|c|c|c|c|c|c|}
\hline \multirow{3}{*}{ Lignin units } & \multirow[b]{3}{*}{$\begin{array}{l}\text { compounds in } \\
\text { smoke }\end{array}$} & \multicolumn{8}{|c|}{ Relative abundance of lignin pyrolysates in smoke emissions from } \\
\hline & & \multicolumn{5}{|c|}{ vineyard smoke exposure experiment } & \multicolumn{3}{|c|}{ prescribed burns } \\
\hline & & Jarrah & Karri & Marri & Oats & Pine & Karri & Marri & Oats \\
\hline \multirow{9}{*}{$\begin{array}{l}\text { p-hydroxy- } \\
\text { phenyls }\end{array}$} & phenol & 54.53 & 48.69 & 45.82 & 56.73 & 33.44 & 35.14 & 14.80 & 34.23 \\
\hline & o-cresol & 9.96 & 8.99 & 9.00 & 11.79 & 7.51 & 6.73 & 3.06 & 5.37 \\
\hline & $\mathrm{m}$ and $\mathrm{p}$-cresol & 17.44 & 23.45 & 9.16 & 13.90 & 14.38 & 11.93 & 13.27 & 7.38 \\
\hline & 2,4-dimethyl phenol & 1.59 & 1.42 & 1.33 & 1.56 & 2.89 & 4.39 & 1.02 & 1.34 \\
\hline & 3,5-dimethyl phenol & $n q$ & $n q$ & 1.23 & 0.44 & 1.28 & $n d$ & $n q$ & 0.67 \\
\hline & 2-ethylphenol & $n q$ & 0.52 & 0.75 & $n q$ & 1.47 & nd & $n q$ & $n q$ \\
\hline & 4-ethylphenol & 3.68 & 1.80 & 2.40 & 2.67 & 4.76 & 2.93 & 3.06 & 4.70 \\
\hline & 4-vinylphenol & $n d$ & $n d$ & $n d$ & $n d$ & 8.66 & $n d$ & $n d$ & 9.40 \\
\hline & 4-allyl phenol & nd & $n d$ & $n d$ & $n d$ & 0.78 & $n d$ & $n d$ & $n d$ \\
\hline \multirow{9}{*}{ guaiacyls } & subtotal & 87.19 & 84.87 & 69.69 & 87.10 & 75.17 & 61.13 & 35.20 & 63.09 \\
\hline & guaiacol & 6.40 & 7.34 & 12.31 & 6.23 & 8.43 & 22.55 & 11.73 & 8.72 \\
\hline & 4-methylguaiacol & 2.54 & 3.15 & 5.81 & 3.11 & 4.81 & 7.98 & 9.69 & 4.70 \\
\hline & 4-ethylguaiacol & 1.78 & 2.55 & 4.90 & 1.45 & 2.43 & 5.42 & 6.63 & 2.01 \\
\hline & 4-vinylguaiacol & 0.25 & 0.45 & 2.40 & 0.67 & 3.99 & 1.54 & 13.27 & 8.72 \\
\hline & eugenol & 0.19 & 0.22 & 1.23 & 0.11 & 1.60 & $n d$ & 1.02 & 0.67 \\
\hline & vanillin & 0.63 & 0.37 & 0.21 & 0.33 & 0.69 & $n d$ & $n d$ & 4.03 \\
\hline & 4-propylguaiacol & 0.19 & 0.15 & 0.75 & $n d$ & 1.19 & $n d$ & $n d$ & $N d$ \\
\hline & $\begin{array}{l}\text { cis- and trans- } \\
\text { isoeugenol }\end{array}$ & $n q$ & $n d$ & nd & 0.22 & 1.47 & nd & nd & 1.34 \\
\hline \multirow{5}{*}{ syringyls } & acetovanillone & $n d$ & $n d$ & $n d$ & $n d$ & 0.23 & $n d$ & $n d$ & $n d$ \\
\hline & subtotal & 11.98 & 14.23 & 27.60 & 12.12 & 24.83 & 37.48 & 42.35 & 30.20 \\
\hline & syringol & 0.82 & 0.90 & 2.72 & 0.78 & nd & 1.39 & 22.45 & 6.04 \\
\hline & 4-methylsyringol & $n d$ & $n d$ & $n d$ & nd & nd & $n d$ & $n d$ & 0.67 \\
\hline & subtotal & 0.82 & 0.90 & 2.72 & 0.78 & nd & 1.39 & 22.45 & 6.71 \\
\hline
\end{tabular}


Table 4. Effects of smoke exposure and fuel type on levels ( $\mu \mathrm{g} / \mathrm{L}$ ) of total phenols (sum of free and glycoside-bound) in wines. Data shown are mean \pm 1 standard error $(n=5)$. ${ }^{1}$ Excludes vanillin and acetovanillone.

\begin{tabular}{|c|c|c|c|c|c|c|c|}
\hline \multirow[b]{2}{*}{ Lignin unit } & \multirow[b]{2}{*}{ putative taint } & \multicolumn{6}{|c|}{ Treatment } \\
\hline & & control & jarrah & karri & marri & wild oats & pine \\
\hline \multirow{6}{*}{$\begin{array}{l}p \text {-hydroxy } \\
\text { phenyls }\end{array}$} & phenol & $5.2 \pm 0.2$ & $29.1 \pm 1.0$ & $20.0 \pm 1.0$ & $40.1 \pm 2.4$ & $46.1 \pm 1.4$ & $35.6 \pm 2.1$ \\
\hline & $o$-cresol & $8.9 \pm 0.3$ & $21.8 \pm 0.4$ & $16.2 \pm 0.9$ & $32.3 \pm 1.0$ & $34.4 \pm 1.2$ & $26.9 \pm 1.7$ \\
\hline & $m$-cresol & $6.3 \pm 0.3$ & $21.4 \pm 0.6$ & $18.6 \pm 0.8$ & $32.6 \pm 1.5$ & $31.2 \pm 0.7$ & $30.2 \pm 1.5$ \\
\hline & $p$-cresol & $9.3 \pm 0.3$ & $22.4 \pm 0.5$ & $19.2 \pm 0.7$ & $34.1 \pm 1.5$ & $32.4 \pm 0.5$ & $31.3 \pm 1.7$ \\
\hline & 4-ethylphenol & $12.4 \pm 0.6$ & $20.7 \pm 1.1$ & $17.7 \pm 0.7$ & $30.5 \pm 1.3$ & $29.4 \pm 0.8$ & $22.8 \pm 0.7$ \\
\hline & subtotal & $42.1 \pm 1.8$ & $115.4 \pm 1.3$ & $91.7 \pm 2.7$ & $169.6 \pm 7.3$ & $173.5 \pm 3.4$ & $146.8 \pm 7.4$ \\
\hline \multirow{6}{*}{ guaiacyls } & guaiacol & $19.2 \pm 0.5$ & $54.7 \pm 2.9$ & $44.5 \pm 1.4$ & $69.6 \pm 2.9$ & $125.1 \pm 1.4$ & $84.4 \pm 6.8$ \\
\hline & 4-methylguaiacol & $8.1 \pm 0.9$ & $29.4 \pm 2.4$ & $18.4 \pm 1.0$ & $35.2 \pm 2.6$ & $33.9 \pm 1.9$ & $58.3 \pm 7.4$ \\
\hline & 4-ethylguaiacol & $\mathrm{nq}$ & $1.9 \pm 0.1$ & $2.0 \pm 0.1$ & $5.9 \pm 0.2$ & $6.2 \pm 0.2$ & $4.9 \pm 0.5$ \\
\hline & 4-propylguaiacol & $\mathrm{nq}$ & $1.2 \pm 0.1$ & $5.1 \pm 0.7$ & $7.6 \pm 0.2$ & $5.8 \pm 0.5$ & $4.3 \pm 0.2$ \\
\hline & 4-vinylguaiacol & $\mathrm{nq}$ & $6.3 \pm 0.4$ & $6.7 \pm 0.4$ & $8.1 \pm 0.5$ & $6.9 \pm 0.9$ & $5.9 \pm 0.3$ \\
\hline & vanillin & $252.2 \pm 19.4$ & $221.8 \pm 33.6$ & $270.6 \pm 18.8$ & $209.0 \pm 14.2$ & $177.6 \pm 13.4$ & $166.2 \pm 9.6$ \\
\hline \multirow{8}{*}{ syringyls } & acetovanillone & $276.0 \pm 8.6$ & $328.2 \pm 18.4$ & $339.2 \pm 9.2$ & $302.0 \pm 4.0$ & $329.3 \pm 12.5$ & $322.7 \pm 13.3$ \\
\hline & subtotal $^{1}$ & $27.3 \pm 0.8$ & $93.5 \pm 4.2$ & $76.7 \pm 1.3$ & $126.4 \pm 4.5$ & $177.9 \pm 2.0$ & $157.8 \pm 14.3$ \\
\hline & syringol & $82.2 \pm 1.3$ & $168.0 \pm 18.1$ & $133.7 \pm 9.8$ & $153.1 \pm 15.2$ & $154.4 \pm 8.6$ & $129.9 \pm 5.9$ \\
\hline & 4-methylsyringol & $\mathrm{nq}$ & $8.4 \pm 0.6$ & $8.8 \pm 0.5$ & $13.1 \pm 0.8$ & $7.9 \pm 0.4$ & $6.8 \pm 0.2$ \\
\hline & syringaldehyde & $48.8 \pm 2.0$ & $67.3 \pm 8.5$ & $86.2 \pm 2.3$ & $54.5 \pm 2.9$ & $47.9 \pm 2.4$ & $52.3 \pm 2.7$ \\
\hline & acetosyringone & $110.5 \pm 9.1$ & $205.4 \pm 15.6$ & $143.2 \pm 15.0$ & $213.4 \pm 19.7$ & $203.0 \pm 19.4$ & $217.3 \pm 11.0$ \\
\hline & subtotal & $241.5 \pm 11.0$ & $449.1 \pm 42.7$ & $371.9 \pm 27.4$ & $434.1 \pm 36.0$ & 413.2 \pm 23.1 & $406.3 \pm 10.2$ \\
\hline & $\begin{array}{l}\text { Total lignin- } \\
\text { derivatives }\end{array}$ & $311.2 \pm 11.1$ & $658.0 \pm 44.2$ & $540.1 \pm 29.6$ & $731.3 \pm 45.0$ & $764.6 \pm 23.7$ & $711.0 \pm 27.5$ \\
\hline
\end{tabular}


Table 5. Effects of fuel type and smoke exposure on levels $(\mu \mathrm{g} / \mathrm{L})$ of glycoconjugated phenols in Merlot wines. Data are mean \pm 1 standard error $(n=5$, each observation is a mean of three analytical determinations); nd, not detected.

\begin{tabular}{|c|c|c|c|c|c|c|c|}
\hline \multirow[b]{2}{*}{ Lignin unit } & \multirow[b]{2}{*}{ bound phenols } & \multicolumn{6}{|c|}{ Treatments } \\
\hline & & Control & Jarrah & Karri & Marri & Wild oats & Pine \\
\hline \multirow{7}{*}{$\begin{array}{c}p \text {-hydroxy- } \\
\text { phenyls }\end{array}$} & phenol & $3.6 \pm 0.2$ & $21.7 \pm 0.4$ & $15.4 \pm 0.4$ & $29.8 \pm 0.6$ & $30.4 \pm 0.6$ & $26.3 \pm 0.7$ \\
\hline & $o$-cresol & $6.9 \pm 0.2$ & $17.1 \pm 0.3$ & $13.7 \pm 0.4$ & $26.4 \pm 0.6$ & $26.2 \pm 0.5$ & $21.5 \pm 0.7$ \\
\hline & $m$-cresol & $5.5 \pm 0.2$ & $17.5 \pm 0.4$ & $16.1 \pm 0.4$ & $27.2 \pm 0.6$ & $25.1 \pm 0.4$ & $25.1 \pm 0.5$ \\
\hline & $p$-cresol & $8.2 \pm 0.2$ & $18.3 \pm 0.4$ & $16.5 \pm 0.4$ & $27.7 \pm 0.8$ & $25.8 \pm 0.3$ & $26.1 \pm 0.6$ \\
\hline & 4-ethylph & $12.4 \pm 0.6$ & $17.7 \pm 0.7$ & $16.0 \pm 0.5$ & $26.7 \pm 0.6$ & $24.1 \pm 0.5$ & $19.2 \pm 0.3$ \\
\hline & & $36.6 \pm 2.0$ & $92.3 \pm 1.8$ & $77.7 \pm 1.4$ & $137.8 \pm 4.6$ & $131.6 \pm 2.2$ & $118.2 \pm 4.0$ \\
\hline & guaiacol & $15.1 \pm 0.4$ & $38.9 \pm 1.2$ & $37.4 \pm 0.7$ & $54.3 \pm 0.7$ & $87.8 \pm 0.8$ & $64.3 \pm 2.8$ \\
\hline \multirow{5}{*}{ guaiacyls } & 4-methylguaiacol & $7.6 \pm 0.5$ & $22.7 \pm 1.0$ & $14.9 \pm 0.4$ & $26.0 \pm 0.9$ & $24.9 \pm 1.0$ & $46.6 \pm 2.9$ \\
\hline & 4-ethylguaiacol & nd & $1.9 \pm 0.1$ & $2.0 \pm 0.1$ & $3.1 \pm 0.1$ & $3.5 \pm 0.1$ & $3.3 \pm 0.2$ \\
\hline & 4-propylguaiacol & nd & nd & $4.0 \pm 0.4$ & $5.1 \pm 0.2$ & $4.3 \pm 0.3$ & $4.3 \pm 0.2$ \\
\hline & 4-vinylguaiacol & nd & $6.3 \pm 0.4$ & $6.7 \pm 0.4$ & $8.1 \pm 0.5$ & $6.9 \pm 0.9$ & $5.9 \pm 0.3$ \\
\hline & & $22.7 \pm 0.7$ & $69.8 \pm 3.2$ & $65.0 \pm 1.4$ & $96.6 \pm 1.8$ & $127.4 \pm 1.6$ & $124.4 \pm 10.5$ \\
\hline \multirow{6}{*}{ syringyls } & syringol & $9.8 \pm 0.6$ & $64.1 \pm 8.1$ & $34.7 \pm 2.6$ & $52.0 \pm 4.9$ & $52.7 \pm 2.6$ & $26.5 \pm 2.5$ \\
\hline & 4-methylsyringol & nd & nd & nd & nd & nd & nd \\
\hline & syringaldehyde & $48.8 \pm 2.0$ & $67.3 \pm 8.5$ & $86.2 \pm 2.3$ & $54.5 \pm 2.9$ & $47.9 \pm 2.4$ & $52.3 \pm 2.7$ \\
\hline & acetosyringone & $13.7 \pm 0.7$ & $30.6 \pm 4.5$ & $24.0 \pm 1.6$ & $25.0 \pm 1.5$ & $10.9 \pm 0.5$ & $9.6 \pm 0.8$ \\
\hline & subtotal & $72.3 \pm 5.9$ & $162.0 \pm 38.3$ & $144.9 \pm 10.2$ & $131.5 \pm 13.1$ & $111.5 \pm 4.2$ & $88.4 \pm 9.4$ \\
\hline & total & $131.6 \pm 5.8$ & $324.1 \pm 25.9$ & $287.6 \pm 10.6$ & $365.9 \pm 15.0$ & $370.5 \pm 10.9$ & $331 \pm 15.1$ \\
\hline
\end{tabular}


Table 6. Effects of fuel type and smoke exposure on volatile phenols levels ( $\mu \mathrm{g} / \mathrm{L})$ in Merlot wines. Data are mean \pm 1 standard error $(n=5$, each observation is a mean of three analytical determinations); nd, not detected.

\begin{tabular}{llcccccc}
\hline \multirow{2}{*}{ Lignin unit } & & \multicolumn{5}{c}{ Treatments } \\
\cline { 3 - 8 } & volatile phenols & Control & Jarrah & Karri & Marri & Wild Oats & Pine \\
\hline \multirow{4}{*}{ Hydroxyl- } & phenol & $1.6 \pm 0.1$ & $7.4 \pm 0.2$ & $4.6 \pm 0.2$ & $10.3 \pm 0.8$ & $15.7 \pm 0.3$ & $9.3 \pm 0.6$ \\
phenyl & o-cresol & $2.0 \pm 0.1$ & $4.7 \pm 0.1$ & $2.5 \pm 0.2$ & $5.9 \pm 0.2$ & $8.2 \pm 0.2$ & $5.4 \pm 0.3$ \\
& p-cresol & $0.8 \pm 0.1$ & $3.9 \pm 0.2$ & $2.5 \pm 0.2$ & $5.4 \pm 0.4$ & $6.1 \pm 0.2$ & $5.1 \pm 0.4$ \\
& 4-ethylphenol & $1.1 \pm 0.1$ & $4.1 \pm 0.1$ & $2.7 \pm 0.1$ & $6.4 \pm 0.3$ & $6.6 \pm 0.2$ & $5.2 \pm 0.4$ \\
& subtotal & $\mathbf{5 . 5} \pm \mathbf{0 . 3}$ & $\mathbf{2 3 . 1} \pm \mathbf{1 . 3}$ & $\mathbf{1 4 . 0} \pm \mathbf{1 . 4}$ & $\mathbf{3 1 . 8} \pm \mathbf{3 . 2}$ & $\mathbf{4 1 . 9} \pm \mathbf{1 . 5}$ & $\mathbf{2 8 . 6} \pm \mathbf{3 . 7}$ \\
& guaiacol & $4.1 \pm 0.2$ & $15.8 \pm 0.5$ & $7.1 \pm 0.2$ & $15.3 \pm 1.2$ & $37.3 \pm 0.4$ & $20.1 \pm 0.9$ \\
guaiacyl & 4-methylguaiacol & $0.5 \pm 0.1$ & $6.7 \pm 0.3$ & $3.5 \pm 0.3$ & $9.2 \pm 0.6$ & $9.0 \pm 0.2$ & $11.7 \pm 1.0$ \\
& 4-ethylguaiacol & nd & nd & nd & $2.8 \pm 0.1$ & $2.7 \pm 0.1$ & $1.6 \pm 0.1$ \\
& 4-propylguaiacol & nd & $1.2 \pm 0.1$ & $1.1 \pm 0.1$ & $2.5 \pm 0.1$ & $1.5 \pm 0.1$ & nd \\
& 4-vinylguaiacol & nd & nd & nd & nd & nd & nd \\
& subtotal & $\mathbf{4 . 6} \pm \mathbf{0 . 3}$ & $\mathbf{2 3 . 7} \pm \mathbf{1 . 2}$ & $\mathbf{1 1 . 7} \pm \mathbf{0 . 5}$ & $\mathbf{2 9 . 8} \pm \mathbf{2 . 9}$ & $\mathbf{5 0 . 5} \pm \mathbf{0 . 7}$ & $\mathbf{3 3 . 4} \pm \mathbf{3 . 8}$ \\
& syringol & $\mathbf{7 2 . 4} \pm 1.0$ & $103.9 \pm 2.3$ & $99.0 \pm 3.2$ & $101.1 \pm 3.7$ & $101.7 \pm 2.5$ & $103.4 \pm 1.5$ \\
syringyl & 4-methylsyringol & nd & $8.4 \pm 0.6$ & $8.8 \pm 0.5$ & $13.1 \pm 0.8$ & $7.9 \pm 0.4$ & $6.8 \pm 0.2$ \\
& syringaldehyde & nd & nd & nd & nd & nd & nd \\
& acetosyringone & $96.8 \pm 5.7$ & $174.8 \pm 6.9$ & $119.2 \pm 7.5$ & $188.4 \pm 10.9$ & $192.1 \pm 10.6207 .7 \pm 8.6$ \\
& subtotal & $\mathbf{1 6 9 . 2} \pm \mathbf{1 0 . 4}$ & $\mathbf{2 8 7 . 1} \pm \mathbf{1 8 . 7}$ & $\mathbf{2 2 7 . 0} \pm \mathbf{1 8 . 5}$ & $\mathbf{3 0 2 . 6} \pm \mathbf{2 6 . 1}$ & $\mathbf{3 0 1 . 7} \pm \mathbf{2 3 . 3 3 1 7 . 9} \pm \mathbf{1 0 . 4}$
\end{tabular}




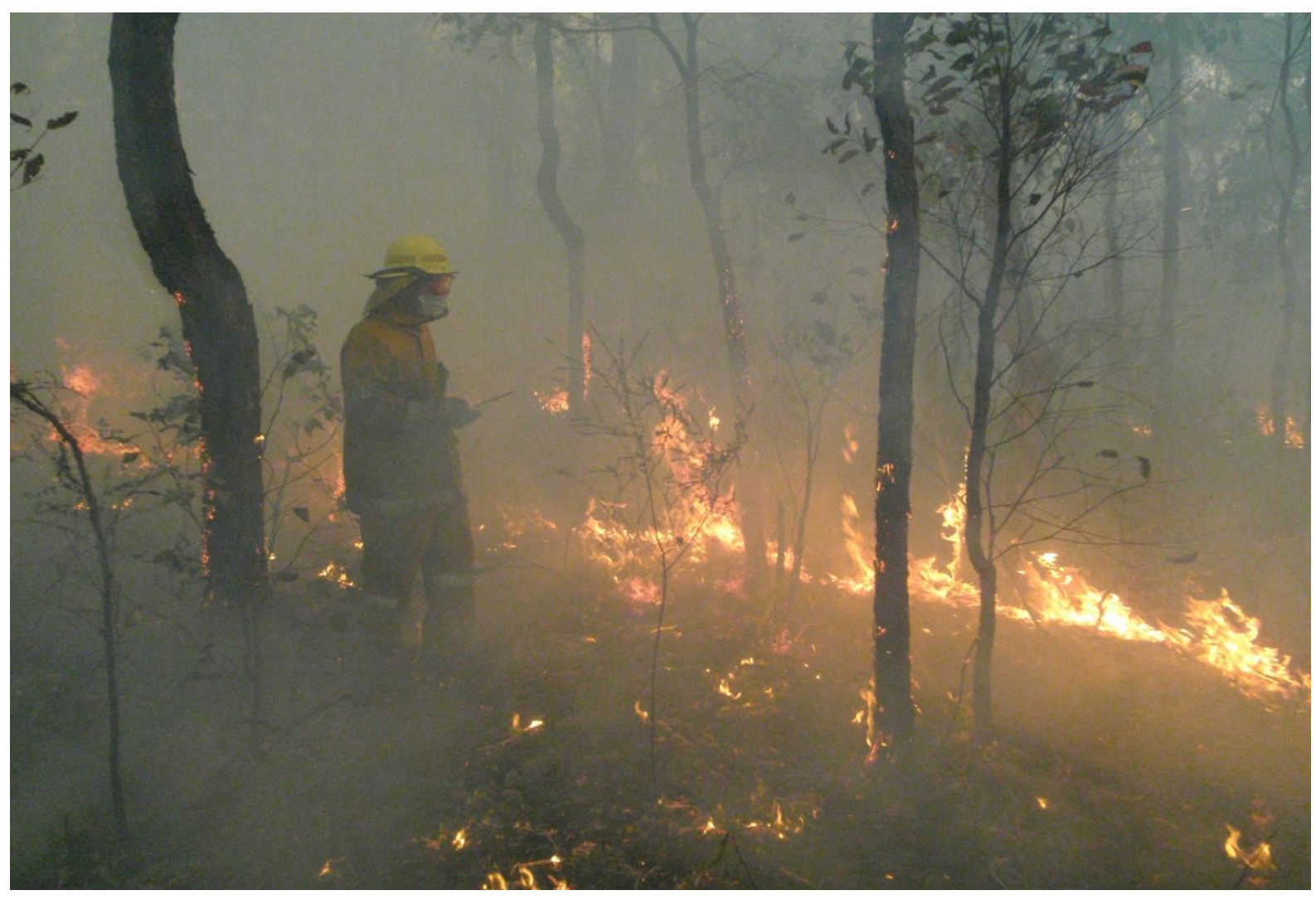

Fig. S1. 


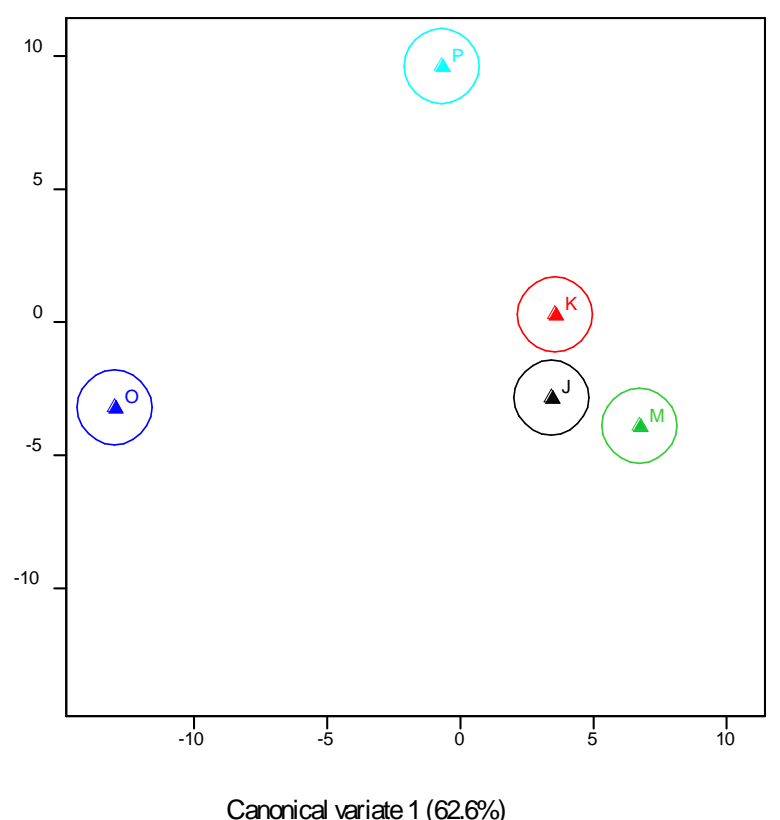

A)

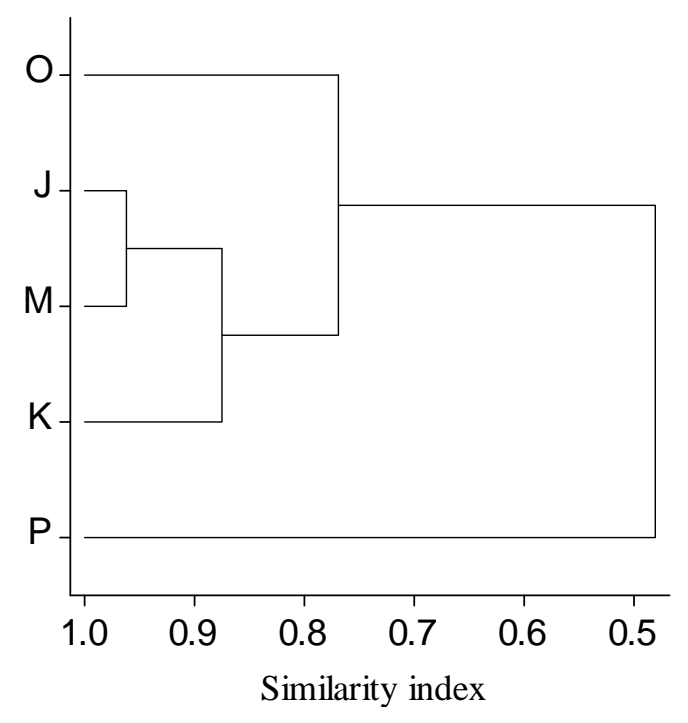

B)

Fig. S2A, B. 
Table S1. Percentage of "biomass" component used for reconstituting fuels used for smoke generation as well as lignocellulose and lignin composition analyses.

\begin{tabular}{|c|c|c|c|c|c|c|}
\hline \multirow[t]{2}{*}{ Fuel } & \multicolumn{5}{|c|}{ Biomass fuel component } & \multirow[t]{2}{*}{ Total } \\
\hline & Leaves & Duff & Bark & $\begin{array}{c}\text { Twigs } \varnothing<6 \\
\text { mm }\end{array}$ & $\begin{array}{c}\text { wood } \varnothing>6 \\
\mathrm{~mm}\end{array}$ & \\
\hline Karri & 50.1 & 26.7 & 3.8 & 14.3 & 5.1 & 100 \\
\hline jarrah & 16.9 & 53.4 & 3.9 & 25.8 & 0.0 & 100 \\
\hline \multirow[t]{2}{*}{ marri } & 16.9 & 53.4 & 3.9 & 25.8 & 0.0 & 100 \\
\hline & Needles & Twigs $\varnothing<5 \mathrm{~mm}$ & $\begin{array}{c}\text { wood } \varnothing 5-20 \\
\mathrm{~mm}\end{array}$ & $\begin{array}{c}\operatorname{wood} \varnothing>20 \\
\mathrm{~mm}\end{array}$ & & \\
\hline \multirow[t]{2}{*}{ pine } & 90.0 & 4.0 & 5.0 & 1.0 & - & 100 \\
\hline & \multicolumn{5}{|c|}{ Straw, blade and panicle } & \\
\hline wild oats & \multicolumn{5}{|c|}{100} & 100 \\
\hline
\end{tabular}

For the tree fuels, the percentages given in Table $\mathrm{S} 1$ are considered to be representative of 10 year old fuel accumulations for the respective vegetation types. For the jarrah fuel, the percentage biomass components were derived from data of Burrows (1994). No such data were found for marri, and its fuel components were approximated using the jarrah ratios since the two species usually co-occur in the southwest forests. Karri fuel components were interpolated to 10 year accumulations from the data published by O'Connell and Menage (1982). For the pine fuel, the components were combined from a comparison of unburnt and wildfire burnt pine plantations in the region. For wild oats, all of its aboveground biomass was considered a single component (100\% fuel source) since all of it combusts during a fire event. 
Table S2. Estimates of vine canopy size, fruit yield and berry quality characteristics.

\begin{tabular}{|c|c|c|c|c|c|c|c|c|c|}
\hline Treat & $\begin{array}{l}\text { LA } \\
\mathrm{m}^{2}\end{array}$ & $\begin{array}{c}\text { Cane } \\
\# \\
\end{array}$ & $\begin{array}{c}\text { Bunch } \\
\# \\
\end{array}$ & $\begin{array}{c}\text { Fruit mass } \\
\mathrm{kg} \\
\end{array}$ & $\begin{array}{c}\text { Mean berry wt. } \\
\mathrm{g}\end{array}$ & $\begin{array}{c}\text { Juice TSS } \\
{ }^{\circ} \text { Brix } \\
\end{array}$ & Juice $\mathrm{pH}$ & $\begin{array}{c}\text { Juice TA } \\
\text { g/l } \\
\end{array}$ & $\begin{array}{c}\text { Malic acid } \\
\mathrm{g} / \mathrm{l}\end{array}$ \\
\hline Control & $37 \pm 5$ & $88 \pm 4$ & $116 \pm 8$ & $22 \pm 1$ & $2.22 \pm 0.09$ & $23.0 \pm 0.2$ & $3.58 \pm 0.03$ & $5.2 \pm 0.3$ & $1.60 \pm 0.08$ \\
\hline Jarrah & $32 \pm 4$ & $90 \pm 2$ & $112 \pm 5$ & $19 \pm 2$ & $2.08 \pm 0.09$ & $22.7 \pm 0.2$ & $3.64 \pm 0.02$ & $4.8 \pm 0.2$ & $1.34 \pm 0.07$ \\
\hline Karri & $36 \pm 3$ & $95 \pm 4$ & $121 \pm 10$ & $22 \pm 2$ & $2.24 \pm 0.06$ & $22.7 \pm 0.2$ & $3.60 \pm 0.01$ & $5.2 \pm 0.1$ & $1.60 \pm 0.02$ \\
\hline Marri & $30 \pm 1$ & $95 \pm 3$ & $116 \pm 7$ & $19 \pm 2$ & $2.16 \pm 0.05$ & $22.6 \pm 0.1$ & $3.62 \pm 0.02$ & $4.9 \pm 0.1$ & $1.50 \pm 0.06$ \\
\hline Oats & $29 \pm 3$ & $100 \pm 6$ & $119 \pm 7$ & $19 \pm 1$ & $2.25 \pm 0.09$ & $22.4 \pm 0.2$ & $3.67 \pm 0.01$ & $4.9 \pm 0.1$ & $1.60 \pm 0.09$ \\
\hline Pine & $31 \pm 2$ & $97 \pm 4$ & $125 \pm 6$ & $23 \pm 4$ & $2.08 \pm 0.09$ & $23.6 \pm 0.9$ & $3.61 \pm 0.02$ & $5.2 \pm 0.1$ & $1.50 \pm 0.09$ \\
\hline
\end{tabular}

To estimate vine canopy size/leaf area, the total number of canes for all vines in each of the 30 panels were counted and recorded shortly after fruit harvest. Then samples of two canes with their subtending leaves were taken from two vines in each panel. The leaves of these sample canes were removed, counted and immediately weighed. Total leaf area for each of these canes was calculated from the average mass of 50 randomly selected $16 \mathrm{~cm}^{2}$ leaf disk cuttings. The total leaf area per panel was then estimated from the product of average leaf area per cane and the total number of canes per panel. There were no significant treatment effects ( $p>0.05$ ) on vine canopy size measures (leaf area and cane numbers), yield and yield components (berry weight, berry and bunch numbers, and fruit yield), as well as harvest quality indicators (levels of total soluble solids, titratable acidity, malic acid and $\mathrm{pH}$ ). 